\title{
Arctigenin Treatment Protects against Brain Damage through an Anti-Inflammatory and Anti-Apoptotic Mechanism after Needle Insertion
}

OPEN ACCESS

Edited by:

Ashok Kumar,

University of Florida, USA

Reviewed by:

Venkata Subba Rao Atluri,

Florida International University, USA

Vinod Tiwari

Johns Hopkins University, USA

${ }^{*}$ Correspondence:

Jing-Xian Yang

421151563@qq.com;

Ting-Guo Kang

ting_guo_kang@126.com

Specialty section: This article was submitted to

Neuropharmacology,

a section of the journal

Frontiers in Pharmacology

Received: 15 April 2016

Accepted: 10 June 2016

Published: 22 June 2016

Citation:

Song J, Li N, Xia Y, Gao Z, Zou S-f, Kong L, Yao Y-J, Jiao Y-N, Yan Y-H,

Li S-H, Tao Z-Y, Lian G, Yang J-X and Kang T-G (2016) Arctigenin

Treatment Protects against Brain

Damage through an

Anti-Inflammatory and Anti-Apoptotic

Mechanism after Needle Insertion.

Front. Pharmacol. 7:182.

doi: 10.3389/fphar.2016.00182
Jie Song ${ }^{1}$, Na Li ${ }^{1}$, Yang Xia ${ }^{2}$, Zhong $\mathrm{Gao}^{3}$, Sa-feng Zou' ${ }^{3}$, Liang Kong', Ying-Jia Yao', Ya-Nan Jiao', Yu-Hui Yan', Shao-Heng Li', Zhen-Yu Tao', Guan Lian', Jing-Xian Yang ${ }^{1 *}$ and Ting-Guo Kang ${ }^{1 *}$

${ }^{1}$ School of Pharmacy, Liaoning University of Traditional Chinese Medicine, Dalian, China, ${ }^{2}$ Department of Engineering, St. Cross College, University of Oxford, Oxford, UK, ${ }^{3}$ Department of Interventional Therapy, Department of Rehabilitation, Dalian Municipal Central Hospital, Dalian, China

Convection enhanced delivery (CED) infuses drugs directly into brain tissue. Needle insertion is required and results in a stab wound injury (SWI). Subsequent secondary injury involves the release of inflammatory and apoptotic cytokines, which have dramatic consequences on the integrity of damaged tissue, leading to the evolution of a pericontusional-damaged area minutes to days after in the initial injury. The present study investigated the capacity for arctigenin (ARC) to prevent secondary brain injury and the determination of the underlying mechanism of action in a mouse model of SWI that mimics the process of CED. After CED, mice received a gavage of ARC from $30 \mathrm{~min}$ to 14 days. Neurological severity scores (NSS) and wound closure degree were assessed after the injury. Histological analysis and immunocytochemistry were used to evaluated the extent of brain damage and neuroinflammation. Terminal deoxynucleotidyl transferase dUTP nick end labeling (TUNEL) was used to detect universal apoptosis. Enzyme-linked immunosorbent assays (ELISA) was used to test the inflammatory cytokines (tumor necrosis factor (TNF)- $\alpha$, interleukin (IL)-6 and IL-10) and lactate dehydrogenase (LDH) content. Gene levels of inflammation (TNF- $\alpha, \mathrm{IL}-6$, and $\mathrm{IL}-10$ ) and apoptosis (Caspase-3, Bax and Bcl-2) were detected by reverse transcription-polymerase chain reaction (RT-PCR). Using these, we analyzed ARC's efficacy and mechanism of action. Results: ARC treatment improved neurological function by reducing brain water content and hematoma and accelerating wound closure relative to untreated mice. ARC treatment reduced the levels of TNF- $\alpha$ and IL-6 and the number of allograft inflammatory factor (IBA)- and myeloperoxidase (MPO)positive cells and increased the levels of IL-10. ARC-treated mice had fewer TUNEL+ apoptotic neurons and activated caspase-3-positive neurons surrounding the lesion than controls, indicating increased neuronal survival. Conclusions: ARC treatment confers neuroprotection of brain tissue through anti-inflammatory and anti-apoptotic effects in a mouse model of SWI. These results suggest a new strategy for promoting neuronal survival and function after CED to improve long-term patient outcome.

Keywords: arctigenin, stab wound injury, inflammation, apoptosis, convection enhanced delivery, traumatic brain injury 


\section{INTRODUCTION}

Traumatic brain injury (TBI) is acquired from an external force, which can inflict devastating effects to the brain tissue, vasculature and neighboring neuronal cells (Logsdon et al., 2015). CED infuses drugs directly into brain tissue (Casanova et al., 2014a), which can result in stab wound injury (SWI), which is a type of TBI.

The success of neurological disorder treatment depends on effective techniques that deliver drugs to the central nervous system (CNS). However, the blood-brain barrier (BBB) prevents passive passage of the majority of large molecules from the bloodstream into the extracellular space, so systemic delivery can be problematic (Abbott and Romero, 1996; Nicholson, 2001). $\mathrm{CED}$ is a technique that delivers therapeutic drugs directly to the CNS, bypassing the BBB (Bobo et al., 1994). In CED, a needle is inserted directly into the brain, and drug infusate is delivered at controlled flow rates into the nidus. With convection as the dominant transport mechanism, this technique can improve local delivery and absorption by providing larger distribution volumes than systemic delivery methods (Bobo et al., 1994; Casanova et al., 2014a). While CED provides a new and effective method for the treatment of nervous system diseases, at the same time, it will cause the injury in the treatment process of insertion.

Convection enhanced delivery requires the surgical insertion of a needle into brain tissue, and this results in SWI. The primary damage of SWI is tissue tear, cell breakage and hemorrhage. However, subsequent secondary injury is the main effect on wound recovery after SWI, includes brain edema, hematoma, and inflammatory and apoptotic responses, etc (Logsdon et al., 2015). Although we have an improved understanding of the pathophysiology that occurs in mechanical brain injury, clinical neuroprotection trials that attempt to pharmacologically prevent cellular death after mechanical brain injury have failed to show consistent improvement in outcome for these patients. The lack of effective therapy to repair injured brain tissue has motivated researchers to focus on stem cells as a potential avenue for regeneration, though much evidence of functional recovery was provided by the use of exogenous stem cells in brain injury in rodent models. However, there are still many questions to be answered, including ethical and theoretical issues, the appropriate source of stem cells, and immune rejection. Due to the lack of effective therapies, the main clinical treatment is to administer nerve nutrition and dehydration drugs, but the effect is not ideal for injury and nervous system recovery. Inflammation and apoptosis is a pathological hallmark of secondary injury of SWI. The focus of modern medical treatment is to control and reduce secondary damage. Seeds of Arctium lappa have been used as a diuretic, anti-inflammatory and detoxifying agent in Chinese traditional medicine. ARC, a bioactive phenylpropanoid dibenzylbutyrolactone component lignin isolated from Arctium lappa, has anti-inflammatory, and anti-apoptotic activities (Lee et al., 2010; Tsai et al., 2011; Gu et al., 2012; Zhang N. et al., 2013).

The release of inflammatory cytokines in cells after injury is a normal immune response, but the overexpression of some pro-inflammatory cytokines, such as IL-6 and TNF-a, are detrimental to wound recovery (Zhai et al., 2015). A previous study by Zhang et al. (2015) reports that ARC decreased lipopolysaccharide (LPS)-induced acute lung inflammation, infiltration of inflammatory cells into bronchoalveolar lavage fluid, and production of pro-inflammatory cytokines. In other reports, ARC had significantly decreased not only carrageenaninduced paw edema but also MPO and eosinophil (EPO) activities in arachidonic acid-induced edematous tissues (Kang et al., 2008).

However, some anti-inflammatory cytokines, such as IL-10, are beneficial to injury recovery (Zhai et al., 2015). Thus, a drug that would increase favorable cytokines and reduce adverse cytokines is best for disease recovery. Hyam et al. (2013) observed that ARC not only peritoneal macrophages but also increased LPS-reduced IL-10 and a cluster of differentiation (CD) 204 expression.

Many plant products have neuroprotective effects such as osthole and ashwagandha. Osthole confers neuroprotection against cortical SWI and attenuates secondary brain injury (Xia et al., 2012). Ashwagandha and its constituent withanolide A confers neuroprotection against $\beta$-amyloid and HIV-1Ba-L (clade B) induced neuro-pathogenesis (Kurapati et al., 2013, 2014). These drugs are derived from traditional medicines which have advantages on relatively minor toxic side effects and long-term usage; it would be helpful to treat diseases of the nervous system. ARC has been shown to act on scopolamineinduced memory deficit mice and to provide a neuroprotective effect on cultured cortical neurons. In our previous study, we investigated the neuroprotective effect of ARC on H89-induced cell damage and its potential mechanisms in mouse cortical neurons and human SH-SY5Y neuroblastoma cells. We found that ARC prevented cell viability loss and reduced intracellular beta amyloid $(A \beta)$ production induced by $\mathrm{H} 89$ in neurons and human SH-SY5Y cells and also inhibited presenilin 1 (PS1) protein level in neurons. Our results showed that ARC confers neuroprotective effects via upregulation of phosphocAMP response element binding protein (P-CREB) in mouse primary neurons and human SH-SY5Y neuroblastoma cells. The reduction of inflammation can contribute to nervous system recovery, improving the neurological dysfunction caused by the injury. A previous study has shown that ARC treatment significantly reduced cerebral infarction and improved neurological outcome through suppressing the activation of microglia and decreasing the expression of IL- $1 \beta$ and TNF- $\alpha$ (Fan et al., 2012).

The release of apoptotic cytokines is a major factor affecting wound and neurological function recovery (Zhai et al., 2015). Inflammation and apoptosis are closely related, and inflammation can cause apoptosis (Fernandes-Alnemri et al., 2009). Therefore, effective drugs can be both anti-inflammatory and anti-apoptotic. In experimental Japanese encephalitis (JE) treatment, ARC provided complete protection against disease. ARC's neuroprotective effect was associated with a marked decreases in microgliosis and proinflammatory cytokines, active caspase-3 activity and neuronal death. Furthermore, treatment with ARC also improves the behavioral outcome following JE (Swarup et al., 2008). 
A

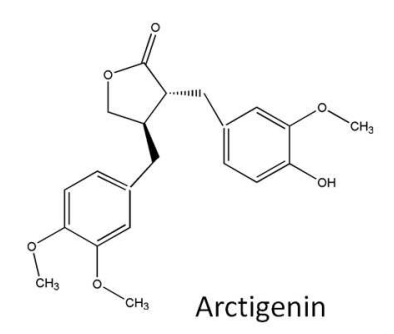

D

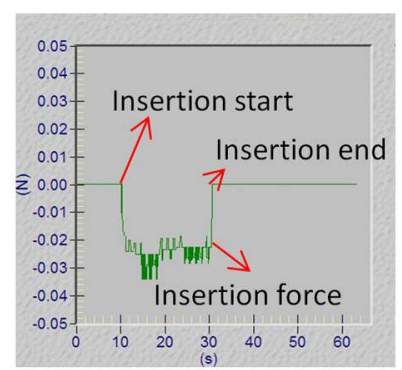

B

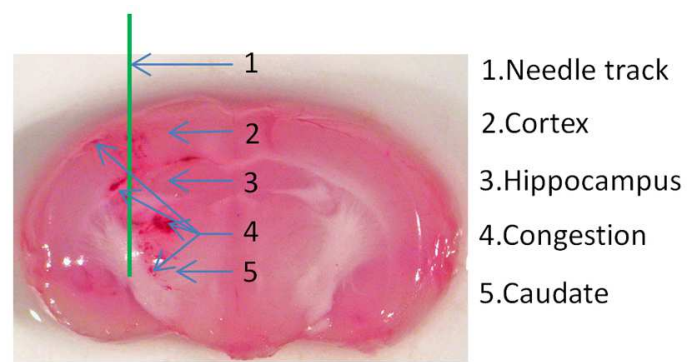

C

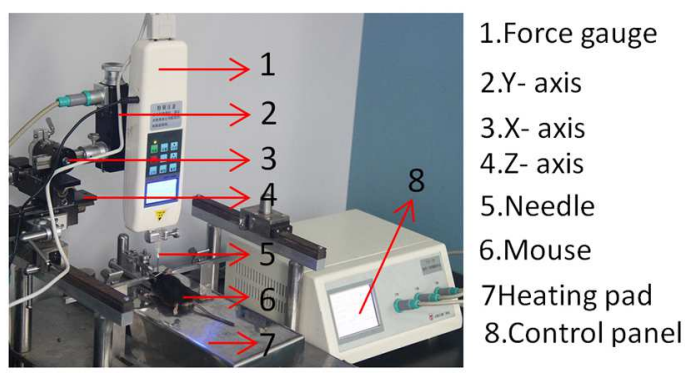

FIGURE 1 | Structure of arctigenin (ARC) and CED system. (A) The chemical structure of ARC. (B) Coronal section of the mouse brain showing a schematic of the needle track (in green). (C) Diagram of mouse model showing the CED system placement and site of stab in SWI brain injury. (D) Typical needle insertion force vs. time for brain tissue. The insertion speed was $0.2 \mathrm{~mm} / \mathrm{s}$, and the insertion force was measured by digital force gage.

Based on the above studies, we assume that ARC treatment can protect against brain damage via anti-inflammatory and antiapoptotic effects in a mouse model of CED-induced brain injury. We observed neurological function, the BBB, inflammation and apoptosis following a 2 -week treatment with ARC. The results suggest a new strategy for restoring neuronal function and improving long-term patient outcomes after CED.

\section{MATERIALS AND METHODS}

\section{Preparation of ARC}

Arctigenin (catalog no. 140524, purity > 98\% (Figure 1A) was purchased from the Chengdu Puei De Biotech Co., Ltd (SIchuan, China), dissolved in sodium carboxyl methyl cellulose (5\% CMC) (Kong et al., 2015), and stored at $4^{\circ} \mathrm{C}$.

\section{Animals}

Adult (25-30 g) C57BL/6J mice aged 3-4 months were housed under a 12:12-h light/dark cycles with free access to food and water. Animal procedures conformed to guidelines set by Liaoning University of Traditional Chinese Medicine Institutional Animal Care and Use Committee, which are in accordance with those set by the National Institutes of Health (Bethesda, MD, USA).

\section{Model}

A mouse model of SWI, as previously described in (Xia et al., 2012; Hu et al., 2013; Gao et al., 2014) with slight modifications, was created to mimic the CED procedure. Briefly, anesthesia was initiated with chloral hydrate $(4 \%, 0.1 \mathrm{ml} / 10 \mathrm{~g})$ delivered at $1.0 \mathrm{ml} / \mathrm{min}$. The head was shaved and disinfected with iodine/alcohol. Animals were fixed on an Autostereotaxic Frame (PTW-1, Chengdu Instrument Factory, China). Body temperature was maintained $\left(37^{\circ} \mathrm{C}\right)$ with a heating pad during the entire procedure. The skull was exposed by a mid-sagittal incision that began between the eyes and extended caudally to the level of the ears to expose the bregma and lambda. A hole of 2-mm diameter was drilled by hand into the skull above the caudate putamen $(\mathrm{CPu})$ over the left cerebral hemisphere. Dura mater was carefully taken off, and any residual blood was cleaned with phosphate-buffered saline $(1 \times$ PBS). A 20-gage, 1.5-mm diameter needle (Hamilton Company, Reno, NV, USA), with a rigid core was inserted $2.5 \mathrm{~mm}$ lateral to the midline, $2.5 \mathrm{~mm}$ posterior to the lambdoidal suture, and at a depth of $4 \mathrm{~mm}$ from the surface of the brain (Figure 1B). The exposed surface of the brain was kept wet with PBS during the course of the experiment. The rigid core was then withdrawn, and the needle was left in situ for 5 min before removal. The skin was then sutured, and mice were allowed to recover in their cages.

\section{Needle Insertion and CED System}

According to studies by Casanova et al. (2014a,b), a stainless steel needle with a blunt tip was used in this study because it has been used in clinical trials. To minimize tissue entering the needle tip, the inner lumen of the needle was filled with cyanoacrylate glue. To ensure the consistency of the experiment, a linear stage (Figure 1D) was used to control needle insertion. The needle was mounted on the $Y$-axis of the linear stage, and mice were fixed on the heating pad with the metal frame to position the mice under the needle. The $X$-axis and $Z$-axis of the linear stage were adjusted such that drilled holes in the rat skull were aligned with the needle tip. The $Y$-axis of the 
linear stage was adjusted such that the needle tip just reached the brain, and subsequently, needles were inserted to a depth of $4 \mathrm{~mm}$ into the brain. To reduce deviation, all processes of needle insertion were controlled by a numerical control panel. The dura mater is considered to be a tough membrane covering that would add excessive surface deformation during needle insertion. Thus, the dura mater was carefully removed before needle insertion. Studies by Casanova et al. (2014a,b) indicated that different speeds of needle insertion can produce different pressures, which can induce different extents of damage. To minimize the effects of speed and pressure changes during insertion, a constant speed $(0.2 \mathrm{~mm} / \mathrm{s})$ was used that produced a stable pressure $(0.029 \pm 0.005 \mathrm{~N})$ (Figure 1C). The insertion force was measured by digital force gage (HF-2, Wenzhou tripod instrument manufacturing CO., LTD, China). The digital force gage monitored the process of insertion in real-time. To reduce injury induced by infusion pressure, a low drug infusion speed was used $(2 \mu \mathrm{L} / \mathrm{min})$. We assume that the dosage of infusion was $10 \mu \mathrm{L}$, so the infusion process takes approximately $5 \mathrm{~min}$. Therefore, to mimic the drug delivery process, the needle must stay in mice for $5 \mathrm{~min}$ after needle insertion.

\section{Drug Use}

Mice were randomly divided into five groups ( $n=6$ each): mice in groups 1-3 (SWI+ARC) were administered ARC intragastrically (ig) $30 \mathrm{~min}$ after surgery at 20, 40, and $80 \mathrm{mg} / \mathrm{kg}$ dissolved in 5\% CMC in PBS followed by once daily intragastrical (ig) administration $(200 \mu \mathrm{l})$ for the next 14 days; mice in the SWI control group were given 5\% CMC in PBS by intragastrical (ig) administration $(200 \mu \mathrm{l})$ each day for 14 days; and naïve C57BL/6J mice were used as controls. Mice were sacrificed between 3 and 21 days post injury (dpi) for analyses.

\section{Assessment of Neurological Function}

Neurological function was assessed with a modified NSS at $24 \mathrm{~h}$ and 3, 7, 14, and $21 \mathrm{dpi}$, as previously described (Lu et al., 2003; Hirjak et al., 2013; Liu et al., 2014). The NSS evaluation consisted of motor, sensory, reflex, and balance tests, with results measured on a scale of $0-18(0=$ normal, $1-$ $6=$ mild injury, $7-12=$ mean-moderate injury; $13-18=$ severe injury, and $18=$ maximal deficit). The test was administered by blinded, trained investigators, and mice were familiarized with the testing environment before being subjected to brain injury.

\section{Measurement of Brain Water Content}

Brain water content was measured 3 days post-SWI. Following decapitation, brains were harvested, and the cerebellum and olfactory bulb was removed. Subsequently, surface liquid was dried with filter paper. The brain wet weight was obtained on a pre-weighed metal box after drying in an electric oven at $105^{\circ} \mathrm{C}$ for $24 \mathrm{~h}$, and the percent water was calculated as (wet weight dry weight)/(wet weight) (Lee et al., 2008; Taya et al., 2010; Xia et al., 2012).

\section{Determination of Albumin Leakage and Brain Hematoma}

Blood-brain barrier permeability was determined by measuring Evans blue (EB) extravasation (Başkaya et al., 1997; Shi et al., 2015). Four percent EB (4 mL/kg; Sigma-Aldrich) was injected into the caudal vein at $3 \mathrm{dpi}$. One hour later, animals were transcardially perfused with cold saline to remove intravascular EB. The brains were removed carefully and visualized on a OLYMPUS SZX9 microscope (Tokyo, Japan) with a digital camera.

To quantify EB extravasation, each brain was carefully weighed and soaked in methanamide for $48 \mathrm{~h}$ at $37.0^{\circ} \mathrm{C}$, then subsequently centrifuged for $30 \mathrm{~min}$ at $20,000 \mathrm{~g}$. The absorption of the supernatant was measured at $632 \mathrm{~nm}$ with a spectrophotometer (Bio-Rad, Hercules, CA, USA). Tissue EB concentration was quantified using a standard curve and expressed as $\mu \mathrm{g} / \mathrm{g}$ of brain tissue.

Brain hematoma volume was determined by ImageJ calculation of the area of congestion at $3 \mathrm{dpi}$. Mice were anesthetized with chloral hydrate $(4 \%, 0.1 \mathrm{ml} / 10 \mathrm{~g})$ then were transcardially perfused with $1 \%$ PBS to remove intravascular blood. The brains were removed carefully and visualized on a OLYMPUS SZX9 microscope (Tokyo, Japan) with a digital camera.

\section{Measurement of Lesion Size}

At 3, 7, 14, and 21 dpi, mice were anesthetized and transcardially perfused with $4 \%$ paraformaldehyde in cold phosphate buffer. Brains were immediately harvested and visualized on a OLYMPUS SZX9 microscope (Tokyo, Japan) with a digital camera. The size of the wound lesion was measured in each brain by tracing a line along the edge of the tissue lining the lesion with ImageJ software (National Institutes of Health) (d'Avila et al., 2012). Measurements were taken from 6 brains at each time point.

\section{Slice Preparation}

Mice were anesthetized with $4 \%$ chloral hydrate $(0.1 \mathrm{ml} / 10 \mathrm{~g}$, i.p.), and then transcardial perfusion with $1 \%$ PBS was performed. Subsequently, $4 \%$ paraformaldehyde was perfused to fix tissue. The brains were harvested and cryo-protected in PBS containing $30 \%$ sucrose until brains sank to the bottom. Then, the brains were equilibrated to optimum cutting temperature compound (OTC) and placed in the freezer. The brains were sectioned into 5-10 mm thick sections with a cryostat (CM1900, Leica). The sections were located in a direction parallel to the needle penetration line at $150 \mu \mathrm{m}$ intervals to cover the entire lesion site. The sections were mounted on glass slides for staining and visualized on a OLYMPUS SZX9 and BX51 microscope (Tokyo, Japan) with a digital camera.

\section{Nissl Staining}

Seven days after SWI, the mouse brains (six per group) were harvested and made into $5 \mu \mathrm{m}$ slices for Nissl staining (Zhao et al., 2014; Zhai et al., 2015). The sections were fixed in absolute ethyl alcohol and then processed through different baths in the 
following order: $100 \%$ ethanol ( $1 \mathrm{~min}), 95 \%$ ethanol ( $1 \mathrm{~min}), 70 \%$ ethanol ( $1 \mathrm{~min})$, double distilled water ( $1 \mathrm{~min}$, three times), cresyl violet $\left(56^{\circ} \mathrm{C}, 1 \mathrm{~h}\right)$, double distilled water ( $1 \mathrm{~min}$, three times), neutral differentiation solution $(2 \mathrm{~min}), 100 \%$ ethanol $(1 \mathrm{~min})$, xylene $(1 \mathrm{~min})$; the samples were then mounted with neutral balata and covered with a coverslip. The Nissl staining sections were visualized on a OLYMPUS SZX9 and BX51 microscope (Tokyo, Japan) with a digital camera.

\section{Hematoxylin and Eosin (H\&E) Staining}

At 3 dpi, the mouse brains (six per group) were harvested and made into $10 \mu \mathrm{m}$ slices for $\mathrm{H} \& \mathrm{E}$ staining (Bitto et al., 2012; Casanova et al., 2014a,b). The sections were dried for $30 \mathrm{~min}$ at room temperature and then processed through different baths in the following order: $70 \%$ ethanol (5 s), 80\% ethanol (5 s), $95 \%$ ethanol ( $5 \mathrm{~s})$, distilled water ( $5 \mathrm{~s}$, three times), hematoxylin (5s, three times), alcohol lamp heating (ten times), distilled water (1 min, three times), $1 \%$ alcohol differentiation solution (3 s, five times), distilled water ( $1 \mathrm{~min}$, three times), 5\% ammonia (3 s, eight times), distilled water (1 min, three times), eosin (10 times), distilled water (1 $\mathrm{min}$, three times), 70\% ethanol (5 s), $80 \%$ ethanol (5 s), 95\% ethanol (5 s), alcohol lamp heating; the samples were then mounted with neutral balata and covered with a coverslip. The H\&E staining sections were visualized on a OLYMPUS SZX9 microscope (Tokyo, Japan) with a digital camera.

\section{Immunofluorescent Staining}

After SWI, the mice (six per group) were sacrificed at 3 days for inflammation examination (Zhang R. et al., 2013) and 7 days for apoptosis examination (Liu et al., 2014). Brains were harvested and made into $5 \mu \mathrm{m}$ slices for immunofluorescent staining. The sections were processed through different baths in the following order: $4 \%$ paraformaldehyde $(30 \mathrm{~min}), 1 \%$ PBS (5 min, three times), $1 \%$ Triton X-100 (30 min), 1\% PBS (5 min, three times), $5 \%$ bull serum albumin (BSA) (30 min), 1\% PBS (5 min, three times), primary antibody (Rabbit Anti-GFAP antibody, Rabbit Anti-AIF1/Iba1 antibody, Rabbit Anti-MPO antibody, Rabbit Anti-NF-M antibody, Rabbit Anti-Caspase-3 antibody) (1:150, Abcam, Cambridge, MA, USA), incubation $\left(4^{\circ} \mathrm{C}, 12 \mathrm{~h}\right)$, $1 \%$ PBS (5 min, three times), secondary antibody (Donkey Anti-rabbit IgG/Cy3 antibody, Donkey Anti-rabbit IgG/FITC antibody) (1:200, Jackson ImmunoResearch Lab, West Grove, PA, USA), incubation (protection from light, $1 \mathrm{~h}$ ), 1\%PBS (5 min, three times), 4',6-diamidino-2-phenylindole (DAPI) (protection from light, $15 \mathrm{~min}$ ), 1\% PBS (5 min, three times); the samples were then mounted with antifade mounting medium and covered with a coverslip. The immunofluorescent staining sections were visualized on a OLYMPUS SZX9 microscope (Tokyo, Japan) with a digital camera.

\section{TUNEL Staining}

TUNEL Universal Apoptosis Detection Kit (Roche, Chicago, IL, USA) was used for the fast detection of fragmented DNA in the nucleus by red fluorescence probe labels during apoptosis. Brain sections from mice at 7 dpi were analyzed for apoptotic cells according to the manufacturer's instructions. The number of TUNEL-positive cells in each section in areas surrounding the lesion were counted in six sections per mouse and six mice per group using ImageJ software.

\section{Analysis of Cytokine Levels by ELISA}

Brains were collected at $3 \mathrm{dpi}$, and the tissue around the cavity (diameter: $5 \mathrm{~mm}$ ) weighing $100 \mathrm{mg}$ was taken. Tissue homogenates were obtained in $900 \mu \mathrm{L} 1 \%$ PBS, and the supernatant was stored at $-80^{\circ} \mathrm{C}$. $\mathrm{LDH}$ (novus biologicals, Littleton, USA, Cat. No. KA0878), TNF- $\alpha$ (Cat. No. MTA00B), IL-6 (Cat. No. M6000B), and IL-10 (Cat. No.M1000B) levels in the samples were measured using ELISA kits (R\&D Systems, Minneapolis, MN, USA) following the manufacturer's instructions (Xia et al., 2012).

\section{Reverse Transcription (RT)-PCR}

Total RNA was extracted from brain tissue at 3 and $7 \mathrm{dpi}$ with TRIzol reagent and reverse transcribed to cDNA using a RevertAid First Strand cDNA Synthesis kit (Thermo Scientific, Vilnius, Lithuania) (Yang et al., 2008). The PCR reaction (35 cycles) was performed using a DreamTaq Green PCR Master Mix Kit (Thermo Scientific). Quantitative RT-PCR was performed using the following forward and reverse primer sets designed using Premier Biosoft 5 (Palo Alto, CA, USA): TNF- $\alpha, 5^{\prime}$-ATA AGA GCA AGG CAG TGG AG-3' and $5^{\prime}$-TCC AGC AGA CTC AAT ACA CA- $3^{\prime} ;$ IL-6, $5^{\prime}$-AGC CAG AGT CCT TCA GAG AG-3' and 5'-TCC TTA GCC ACT CCT TCT GT-3'; IL-10, 5' TTC TCA TTC CTG CTT GTG GC-3' and $5^{\prime}$-ATC TGA GTG TGA GGG TCT GG-3'; Bax, $5^{\prime}$-CTG ACA TGT TTT CTG ACG GC-3' and 5'-TCA GCC CAT CTT CTT CCA GA-3'; Bcl-2, 5' CGC TGG GAG AAC AGG GTA-3' and $5^{\prime}$-GGG CTG GGA GGA GAA GAT-3'; Caspase-3, 5'-AGA TAC CGG TGG AGG CTG ACT-3 $3^{\prime}$ and $5^{\prime}$-TCT TTC GTG AGC ATG GAC ACA-3'; and $\beta$-actin (control), $5^{\prime}$-GGG AAA TCG TGC GTG ACA T$3^{\prime}$ and $5^{\prime}$-TCA GGA GGA GCA ATG ATC TTG-3'. Products were resolved by $1.5 \%$ agarose gel electrophoresis with ethidium bromide staining. The mRNA levels of TNF- $\alpha$, IL- 6 and IL-10 were detected at $3 \mathrm{dpi}$, and those of Bax, Bcl-2, and caspase-3 were detected at $7 \mathrm{dpi}$. Quantitative analysis was performed using a Tanon 4100 Gel Imaging System (Tanon Science \& Technology Co., Shanghai, China).

\section{Measuring Cell Fluorescence Using ImageJ}

The fluorescent intensity was quantified by ImageJ, using the follow steps: Select the cell of interest using any of the drawing/selection tools (i.e., rectangle, circle, polygon, or freeform); From the Analyze menu select "set measurements". Make sure that the AREA, INTEGRATED DENSITY, and MEAN GRAY VALUE have been selected; Select "Measure" from the analyze menu. A popup box will appear with a stack of values for that first cell; Select a region next to the cell that has no fluorescent, this will be located in the background; Repeat this step for the other cells in the field of view that needs to be measure; Once finished, select all the data in the Results window, copy and paste into a new excel worksheet; Use this formula 

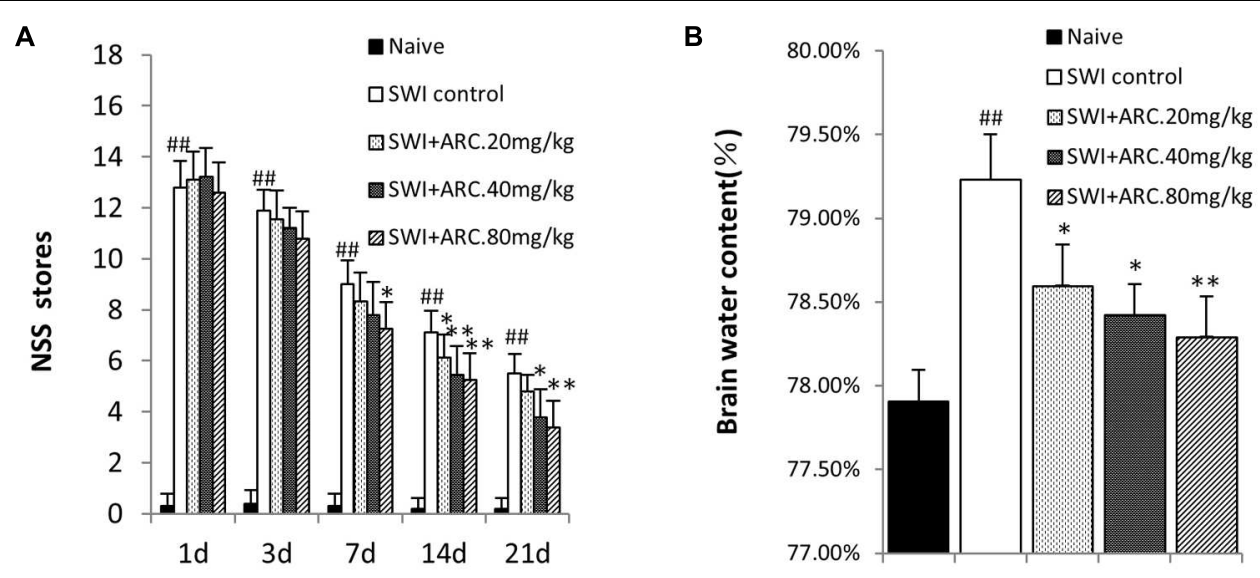

FIGURE 2 | Modified neurologic severity score and brain water content by ARC treatment. (A) Neurological function was analyzed by NSS at 1, 3, 7, 14, and 21 days post injury (dpi). Treatment with ARC significantly lowered NSS from 3 to 21 dpi compared to untreated control. (B) Brain water content of injured hemispheres was measured at $3 \mathrm{dpi}$. The untreated SWI group had a significantly higher brain water content than naive control. ARC treatment significantly reduced brain water contents in a dose-dependent manner. $n=6$ per group. The data are presented as the mean \pm SD. ${ }^{\#} P<0.01$ vs. naive control; ${ }^{*} P<0.05$,

$* * P<0.01$, vs. SWI control.

to calculate the corrected total cell fluorescence (CTCF). More details of the operation can be viewed in the ImageJ's instructions on Measuring Cell Fluorescence.

\section{Statistical Analysis}

The data were analyzed using SPSS version 13.0 (SPSS, Chicago, IL, USA) and are presented as the mean \pm SD. Differences between groups were assessed by one-way analysis of variance, and post hoc multiple comparisons were performed with the Student-Newman-Keuls test. $P<0.05$ was considered statistically significant.

\section{RESULTS}

In the present study, we use naïve (uninjured) mice as controls rather than those subjected to craniotomy. In a previous study, minor injury craniotomy was shown to induce acute inflammatory response (Bayir et al., 2003; Cole et al., 2011). After craniotomy, mice had similar numbers of glial fibrillary acidic protein (GFAP)-positive astrocytes compared to experienced moderate cortical impact injury mice (Susarla et al., 2014).

\section{ARC Treatment Improves Neurological Function after SWI}

To determine whether ARC has neuroprotective effects after SWI, the curative effect of different concentrations of ARC (20, 40 , or $80 \mathrm{mg} / \mathrm{kg} /$ day) were evaluated using an NSS system. NSS was evaluated from 1 to $21 \mathrm{dpi}$. As shown in Figure 2A, ARC treatment improves neurological function from 3 to 21 days compared to naïve control mice. ARC treatment decreased the NSS in a dose-dependent manner, and the administration of a high dose $(80 \mathrm{mg} / \mathrm{kg})$ decreased the NSS the most significantly compared to the middle and low dose. At 3 dpi, we observed that ARC showed a certain treatment effect of decreasing the
NSS in various concentrations, but no significant difference was found between ARC-treated and SWI control group. Regarding $7 \mathrm{dpi}$, the treatment effect of ARC increased remarkable and had significant difference $(7.25 \pm 1.04$ vs. $9.00 \pm 0.93 ; P<0.05$ vs. SWI control at $7 \mathrm{dpi}$ ) between the highest dose group and that of SWI control. The treatment effect increased until $21 \mathrm{dpi}$ in various concentrations $(3.38 \pm 1.06$ vs. $5.50 \pm 0.75 ; P<0.01$ vs. SWI control at $21 \mathrm{dpi})$.

\section{ARC Treatment Decreases Brain Edema Caused by Injury}

Brain edema is caused by damage of the BBB after TBI, and brain water content increase is a marker for brain damage (Zhang R. et al., 2013). A second opening of the BBB will occur due to the inflammation response at 3 dpi (Başkaya et al., 1997). In the present study, different concentrations of ARC were tested to determine whether treatment can lower the brain water content by reducing the inflammatory response 3 days after injury. As shown in Figure 2B, the highest brain water content was in the SWI compared to the naïve control and administration group $(79.23 \% \pm 0.27 \%$ vs. $77.91 \% \pm 0.19 \%)$; ARC treatment decreased the brain water content in a dosedependent manner, and the most significant decrease was observed with $80 \mathrm{mg} / \mathrm{kg}$ ARC $(78.29 \% \pm 0.24 \%$; $P<0.01$ vs. SWI control).

\section{ARC Treatment Accelerates Wound Healing after SWI}

The most direct way to analyze wound healing is to observe the wound size in the brain cavity caused by needle insertion. The size of the brain cavity was measured at four different time points $(3,7,14$, and $21 \mathrm{dpi})$ after injury. As shown in Figure 3A, the size of the brain cavity gradually becomes smaller with the passage of time, but the size of the ARC treatment group is smaller than SWI control mice at each time point. Cavity size 


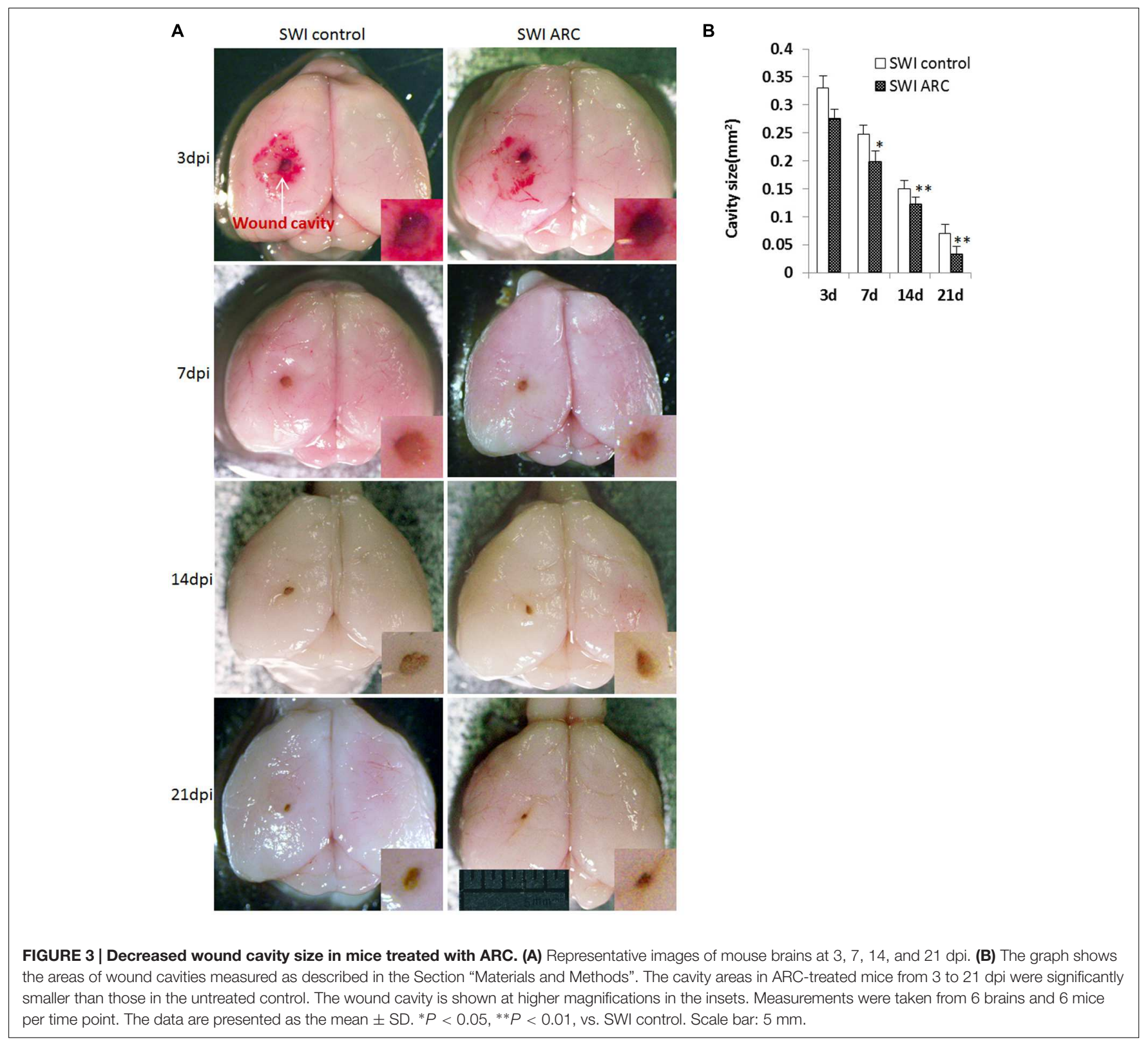

was smallest at $21 \mathrm{dpi}$ in ARC-treated mice, and thus, ARC treatment accelerates wound healing after SWI. By $21 \mathrm{dpi}$, the cavity was smallest in 3/6 ARC-treated mice vs. 5/6 untreated controls $\left(0.033 \pm 0.0041 \mathrm{~mm}^{2}\right.$ vs. $\left.0.070 \pm 0.0054 \mathrm{~mm}^{2} ; P<0.05\right)$ (Figures 3A,B).

\section{ARC Treatment Decreases Albumin Leakage and Brain Hematoma Caused by Injury}

Traumatic brain injury can inflict devastating effects to the brain vasculature and neighboring neuronal cells. Vasculature disruption and increased $\mathrm{BBB}$ permeability are primary effects that can lead to a host of secondary injury cascades (Logsdon et al., 2015). Primary damage of the BBB leads to brain hemorrhage and Albumin Leakage, which occur immediately after TBI, and a second opening of the BBB will occur due to the inflammation response at 3 dpi (Başkaya et al., 1997). In this study, EB leakage was tested to determine whether ARC treatment preserves $\mathrm{BBB}$ integrity via anti-inflammatory effects after SWI. As shown in Figures 4B,D, the volume of EB extravasation was significantly decreased in ARC-treated mice compared to SWI control mice (EB: $2.64 \pm 0.36 \mu \mathrm{g} / \mathrm{g}$ vs. $5.47 \pm 0.64 \mu \mathrm{g} / \mathrm{g} ; P<0.05)$. If ARC treatment protects BBB integrity, the volume of brain hemorrhage should also reduce. Consistent with this, brain hematomas were detected, and the result in Figures 4A,C shows that the volume of brain hematoma was significantly decreased in ARC-treated compared to SWI control mice $\left(1.56 \pm 0.26 \mathrm{~mm}^{2}\right.$ vs. $2.35 \pm 0.25 \mathrm{~mm}^{2}$; $P<0.05)$. 


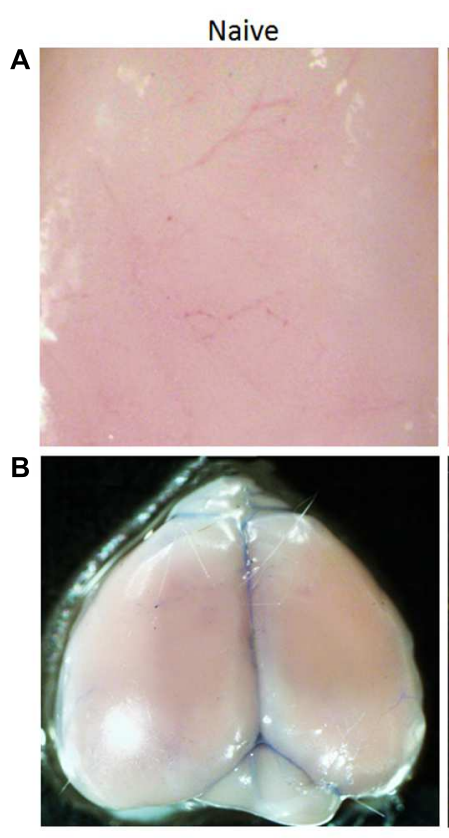

C

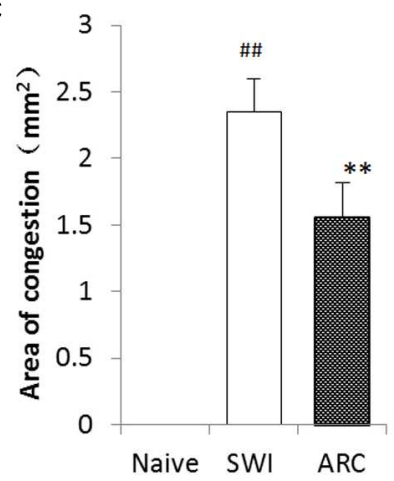

SWI
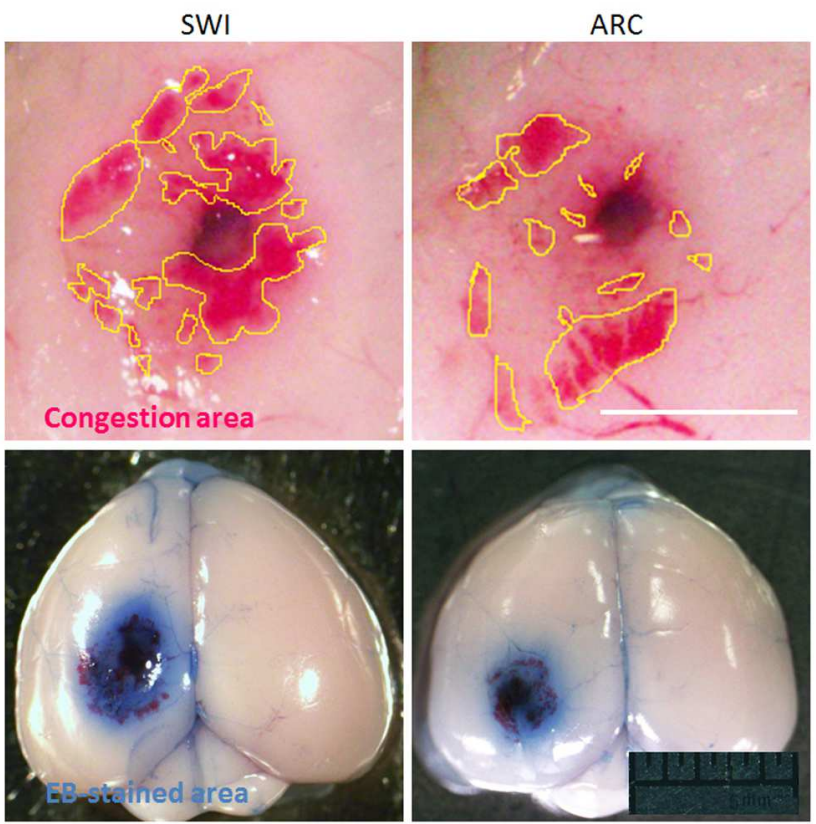

D

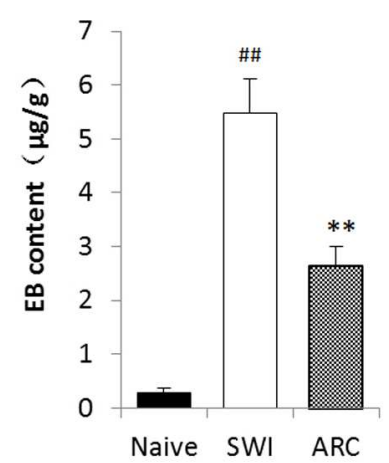

FIGURE 4 | Arctigenin treatment preserves BBB integrity and blood exudation after SWI. (A) Representative images of the congestion area of the brain at 3 dpi after SWI. Yellow lines delimit the congestion area. The area of congestion was reduced in the ARC- treated SWI brain compared to the untreated brain.

(B) Representative images of EB-stained brain at 3 dpi after SWI. The EB-stained areas were reduced in ARC-treated SWI brain compared to the untreated brain.

(C) Quantitative results of the congestion area ( $n=6 /$ group) calculated by Image $\mathrm{J}$ software. (D) Quantitative results of EB extravasation in each brain ( $n=6 /$ group), expressed as EB content $(\mu \mathrm{g} / \mathrm{g})$ calculated from a standard curve. The data are presented as the mean $\pm \mathrm{SD}$. ${ }^{\# \#} P<0.05$ vs. naive control; ${ }^{* *} P<0.01$, vs. SWI control. Scale bar: $0.5 \mathrm{~mm}$ in (A), $5 \mathrm{~mm}$ in (B).

\section{ARC Treatment Suppresses the Inflammatory Response Caused by Injury}

Lactate dehydrogenase (LDH) was used to evaluate the extent of cell damage. LDH is released during tissue damage and is a marker of common injuries. The brain tissue broke down and neural cells were damaged after SWI (Zhao et al., 2012), and then the damaged cells released inflammatory cytokines (Zhang et al., 2012; Gao et al., 2014). Pro-inflammatory cytokines can activate astrocytes, and in turn, activated astrocytes release proinflammatory cytokines such as IL-6 and TNF- $\alpha$ (Lau and Yu, 2001; Ziebell and Morganti-Kossmann, 2010). Macrophages and neutrophils act as the first and main forms of active immune defense, and microglia are a type of glial cells that are the resident macrophages in the brain. After TBI, neutrophils and microglia were activated, and this was the main feature of neuroinflammation (Wang et al., 2007; Clausen et al., 2009). Microglia can also release IL- 6 and TNF- $\alpha$. At 3 days after injury, a large number of inflammatory cytokines were released, and a large number of inflammatory cells were activated (Figure 5A). Thus, the time point 3 dpi was chosen to test the role of ARC in the inflammatory response (Xia et al., 2015). As shown in Figures 5B-D, the numbers of Iba-1+ macrophages/microglia and $\mathrm{MPO}+$ neutrophils in the lesioned cortex significantly decreased in the ARC treatment group compare to the untreated group; however, the numbers of GFAP+ astrocytes did not change, and there was no significant difference in the results of the experiment. (GFAP+: $217.33 \pm 35.30$ vs. $219.311 \pm 42.96$ cells/mm2; Iba-1+: $115.33 \pm 47.96$ vs. $247.83 \pm 52.29$ cells $/ \mathrm{mm} 2$; 

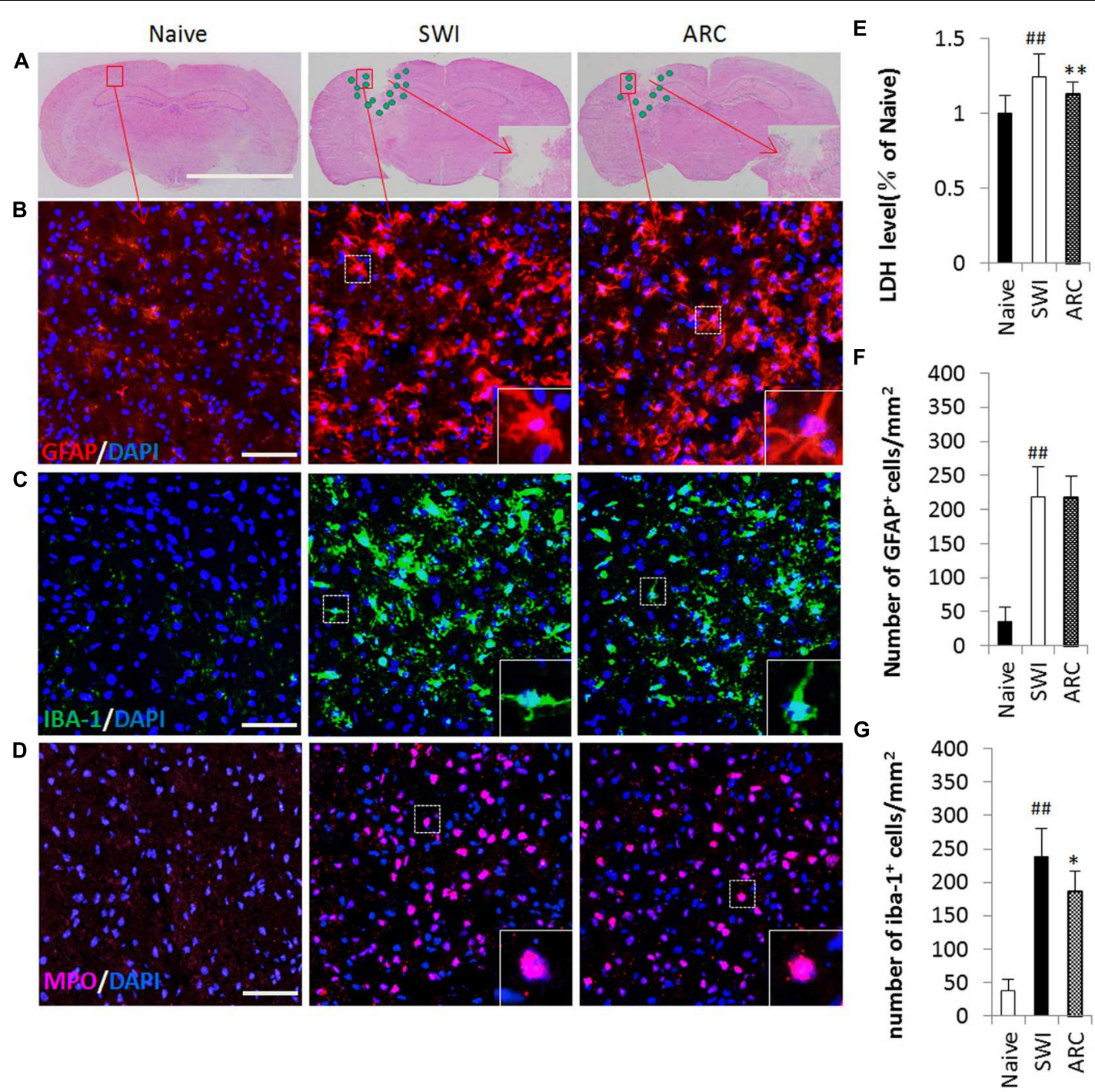

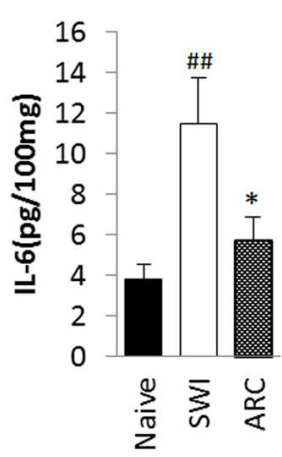

$\mathbf{J}$

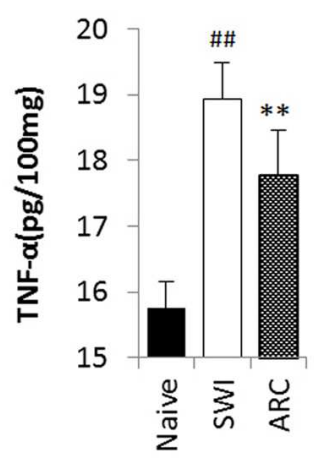

K

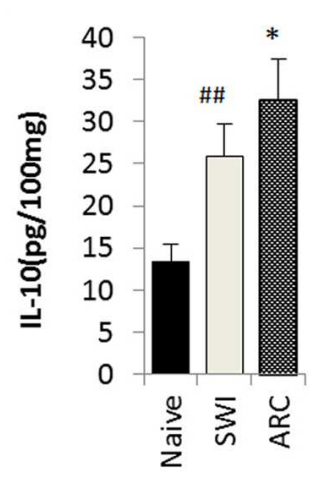

H

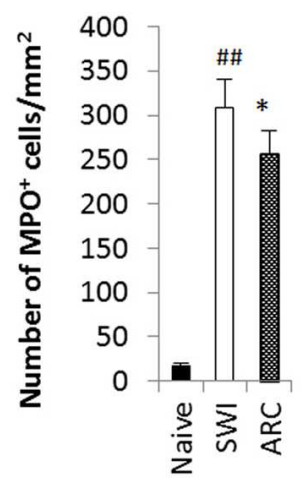

FIGURE 5 | Reduced inflammatory cell infiltration and pro-inflammatory cytokine levels as a result of ARC treatment. (A) Illustration of the spatial distribution of inflammatory cells. The cells were distributed around the lesion at 3 dpi. (B-D) Images of GFAP+, Iba-1+, and MPO+ cells by immunohistochemistry in a single field (box) in the lesioned cortex. Macrophages/microglia (lba-1+ green), neutrophils (MPO+, red) and astrocytes (GFAP+, red) with nuclear DAPI staining (blue). (E) LDH was measured to evaluate the extent of cell damage. (F-H) Quantification of the inflammatory cells among the total number of cells (DAPI+). All groups were examined in the regions immediately surrounding the lesion. Boxed areas appear at higher magnifications in the insets. Scale bar: $5 \mathrm{~mm}$ in (A), $50 \mu \mathrm{m}$ in (B-D). (I-K) Levels of the proinflammatory cytokines IL-6, TNF- $\alpha$, and IL-10 assessed by ELISA assay. The data are presented as the mean \pm SD, $n=6$ per group. ${ }^{\# \#} P<0.01$ vs. naive control; ${ }^{*} P<0.05,{ }^{* *} P<0.01$, vs. SWI control. 
MPO+: $256.67 \pm 61.99$ vs. $309.06 \pm 52.67$ cells $/ \mathrm{mm} 2$, $P<0.01$ ) (Figures 5F-H). We also measured the levels of proinflammatory cytokines (IL- 6 and TNF- $\alpha$ ) and anti-inflammatory cytokines (IL-10) in cortical tissue homogenates by ELISA at 3 dpi. As shown in Figures 5E,I,J,K, ARC reduced the levels of LDH and pro-inflammatory cytokines TNF- $\alpha$ and IL- 6 and increased the level of IL-10 in ARC-treated relative to untreated control animals (LDH: $1.13 \pm 0.087$ vs. $1.24 \pm 0.15$; TNF- $\alpha$ : $17.78 \pm 0.55$ vs. $18.93 \pm 0.68 \mathrm{pg} / 100 \mathrm{mg}$; IL-6: $5.71 \pm 0.041$ vs. $11.47 \pm 0.054 \mathrm{pg} / 100 \mathrm{mg}$; IL-10: $32.60 \pm 0.068$ vs. $25.85 \pm 0.079$ pg/100 mg; P $<0.01)$.

\section{ARC Treatment Reduces Apoptosis and Increases Neuronal Survival in the Injured Brain}

The physical forces of TBI can shear axons (Raghupathi and Margulies, 2002) and break down neurons and its neighboring cells (Figure 6A), eventually resulting in axon loss and neuron and cell death (Clark et al., 1997). The most serious cell death occurred at 7 days after injury, and thus the time point $7 \mathrm{dpi}$ was chosen to examine the role of ARC in the apoptotic response (Xia et al., 2015). To assess the effects of ARC treatment at the cellular level, brain sections were tested for Nissl staining (Figures 6B,F) and neurofilament medium polypeptide (NF-M) expression (Figures 6C,G) at $7 \mathrm{dpi}$, and apoptotic cells were detected by the TUNEL assay (Figures 6E,I) and by examining caspase-3 expression (Figures 6D,H). As Nissl stained images show in Figure 6B, the number of neuronal cells increased significantly in the ARC treatment group compared to untreated mice (Nissl+:113.17 \pm 12.60 vs.105.34 \pm 10.51) (Figure 6F). Axons decreased significantly in SWI control mice and resulted in lowered expression of NF-M. However, ARC treatment increased expression of NF-M in treated mice (Figure 6C). (fluorescence intensity: $75.55 \pm 10.36$ vs. $62.91 \pm 8.32 ; P<0.05$ ) (Figure 6G). The number of TUNEL+ and caspase-3+ cells decreased significantly in the ARC-treated lesion area compared to untreated controls (TUNEL+: $84.25 \pm 17.99$ vs. $129.03 \pm 23.73$ cells $/ \mathrm{mm}^{2}$; caspase-3+: $72.58 \pm 14.54$ vs. $124.81 \pm 16.72$ cells $/ \mathrm{mm}^{2} ; P<0.05$ ) (Figures $6 \mathrm{D}, \mathbf{E}, \mathbf{H}, \mathbf{I}$ ). Thus, ARC promotes neuronal recovery by inhibiting apoptosis after SWI.

\section{ARC Treatment Suppresses the Inflammatory Response and Inhibits Apoptosis at the Gene Level}

To clarify the potential mechanisms of anti-inflammatory and anti-apoptotic functions of $\mathrm{ARC}$, we determined the levels of mRNA expression of pro-inflammatory cytokines (TNF- $\alpha$, IL6) and anti-inflammatory cytokine IL-10 and apoptotic factors caspase-3, Bax and Bcl-2 by RT-PCR. As shown in Figure 7A, SWI induced an increase in TNF- $\alpha$, IL-6, IL-10, Bax, and Caspase- 3 and a decrease in Bcl-2 transcription. ARC treatment resulted in downregulation of TNF- $\alpha$, IL- 6 and caspase-3, a reduction in the ratio of Bax to Bcl-2 and upregulation of IL-10 compared to the untreated SWI group (TNF- $\alpha$ : $0.165 \pm 0.009$ vs. $0.204 \pm 0.015$; IL- 6 : $0.241 \pm 0.016$ vs. $0.283 \pm 0.018$; IL10: $0.221 \pm 0.012$ vs. $0.139 \pm 0.012$; caspase- 3 : $0.117 \pm 0.010$ vs. $0.012 \pm 0.06$; $\mathrm{Bax}$ to $\mathrm{Bcl}-2$ ratio: $0.499 \pm 0.083$ vs. $1.823 \pm 0.165 ; \mathrm{P}<0.01$ ) (Figures 7B-F). Thus, ARC exerts antiinflammatory effects via inhibition of TNF- $\alpha$ and IL- 6 expression and promotion of IL-10 expression and confers anti-apoptotic effects by reducing the $\mathrm{Bax}$ to $\mathrm{Bcl}-2$ ratio and downregulating caspase-3 expression.

\section{DISCUSSION}

After CED, the brain will be damaged by penetration as TBI. Following TBI, there are immediate primary effects and subacute secondary effects. Primary effects to the brain from TBI cause damage to neurons, glia, normal cells, and the cerebral vasculature. Secondary effects to the brain from TBI include inflammatory responses (Farook et al., 2013), cellular stress (Xia et al., 2015), apoptotic cascades (Clark et al., 1997), and loss of axons (Raghupathi and Margulies, 2002). Secondary effects are the main factors that affect the recovery of damage in later stages and are caused by primary effects. In this study, we mainly investigated the secondary injury treatment of ARC after CED.

In an animal model, we mimicked the procedure of CED by using a needle to create a SWI in the mouse brain and investigated whether ARC treatment could protect against secondary brain damage. In this study, ARC protected against $\mathrm{BBB}$ damage, reduced the number of microglia/macrophages in the brain cortex, decreased the number of peripheral infiltrating leukocytes at the lesion, reduced proinflammatory cytokine levels, increased anti-inflammatory cytokine levels, and inhibited apoptosis. These effects were exerted via upregulation of IL-10 and downregulation of IL- 6 , TNF- $\alpha$, and caspase- 3 expression and a reduction in the ratio of $\mathrm{Bax}$ to $\mathrm{Bcl}-2$ at gene level. Thus, ARC can prevent secondary brain damage through antiinflammatory as well as anti-apoptotic mechanisms.

Cerebral hemorrhage and cerebral edema occurred after CED due to the severely damaged BBB. Previous studies have indicated that the occurrence of cerebral hemorrhage is followed by $\mathrm{BBB}$, which is a universal and crucial pathophysiological change (Kastrup et al., 2008). Intracerebral hemorrhage can lead to serious brain tissue damage, such as cerebral hematoma after disruption of the BBB. The level of severity of hematoma is closely related to the clinical prognosis of patients (Wang, 2010; Loftspring et al., 2011; Moxon-Emre and Schlichter, 2011). In this study, we investigated the brain water content, the BBB permeability and the brain hematoma volume as a result of ARC treatment at $3 \mathrm{dpi}$. The results showed that ARC treatment protected against $\mathrm{BBB}$ damage by reducing the brain water content, the $\mathrm{BBB}$ permeability and the volume of brain hematomas. The $\mathrm{BBB}$ will open again at $3 \mathrm{dpi}$ due to the inflammatory response (Başkaya et al., 1997). In previous studies (Zhao et al., 2009; Kou et al., 2011) and this study, results indicate that ARC confers antiinflammatory effects, which is the potential mechanism of BBB protection.

After TBI, the damaged cells released $\mathrm{LDH}$ and inflammatory cytokines that can cause neuroinflammation. Neuroinflammation is characterized by macrophage and 


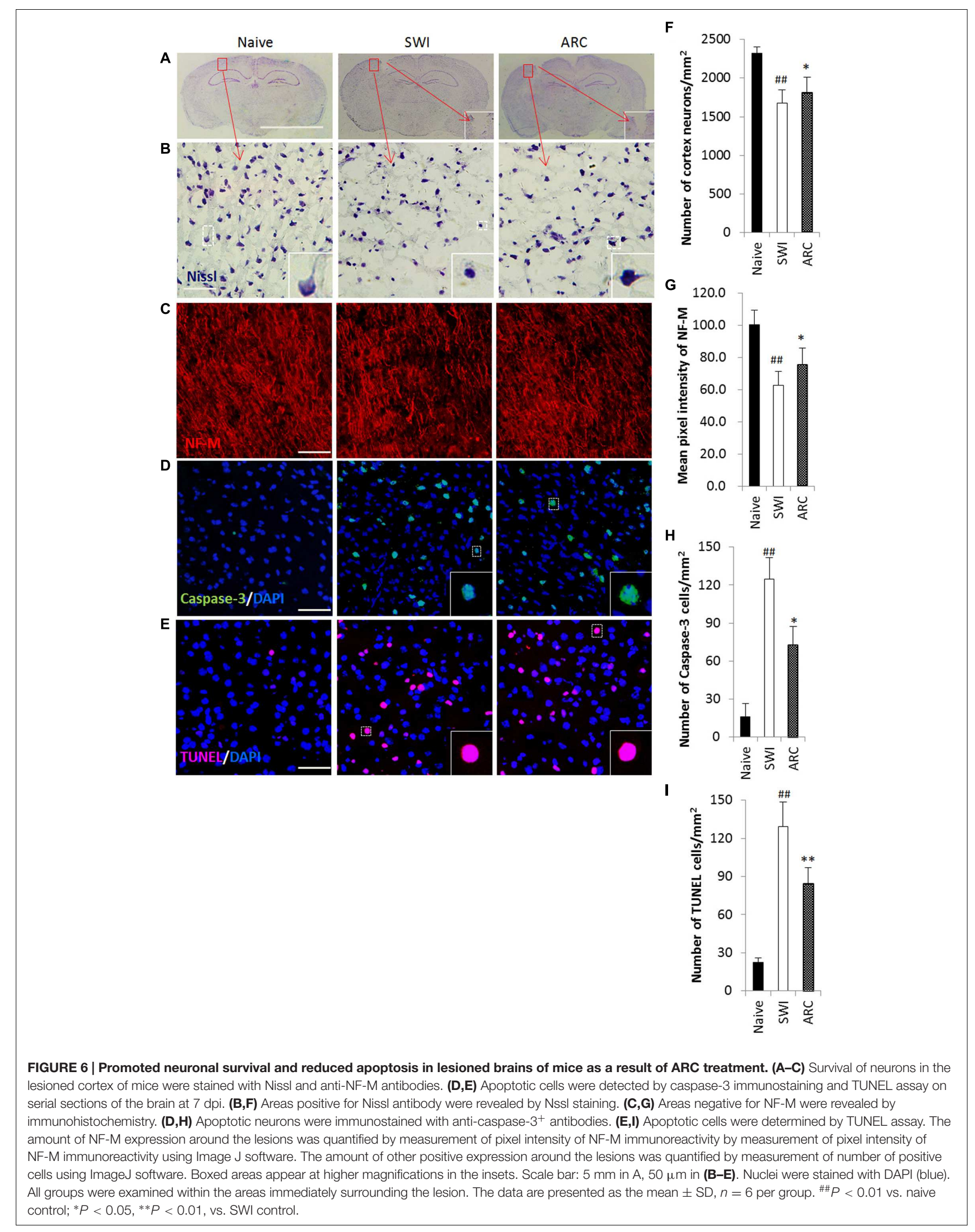




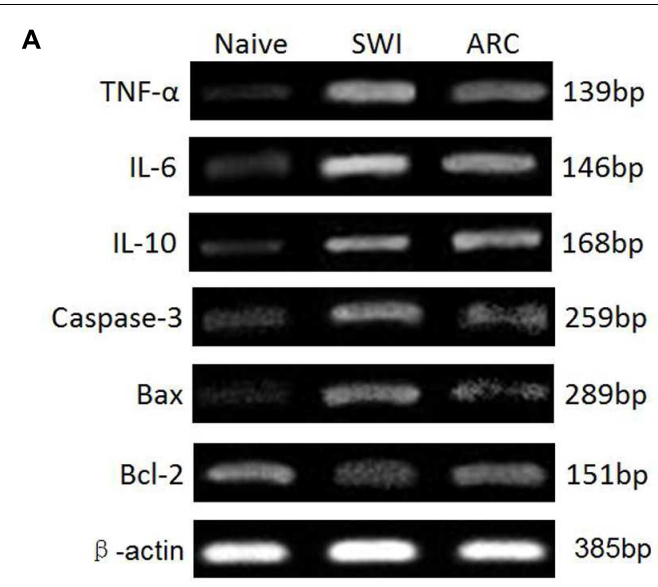

B

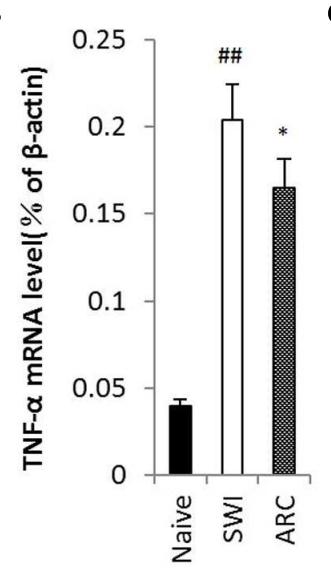

C

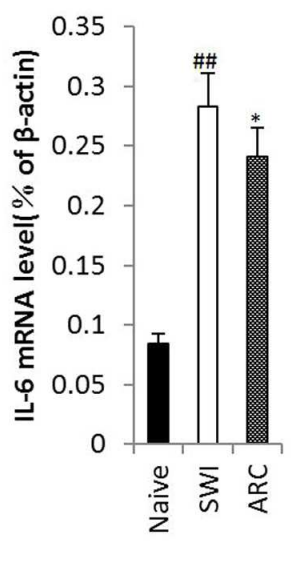

E

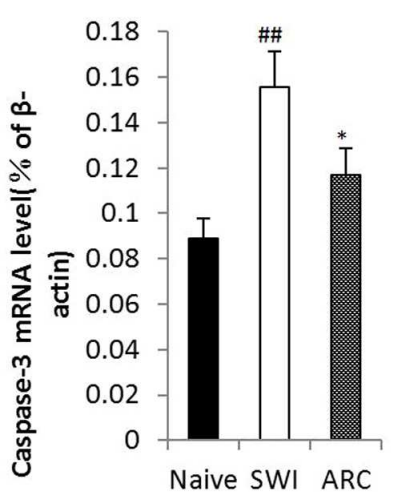

D

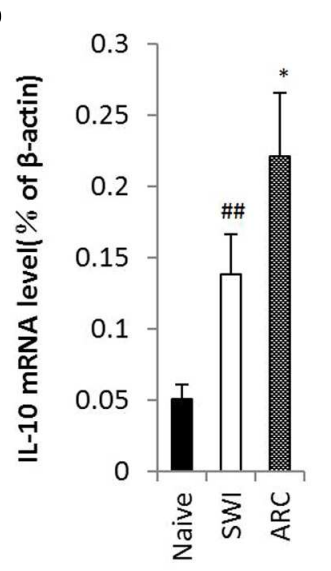

F

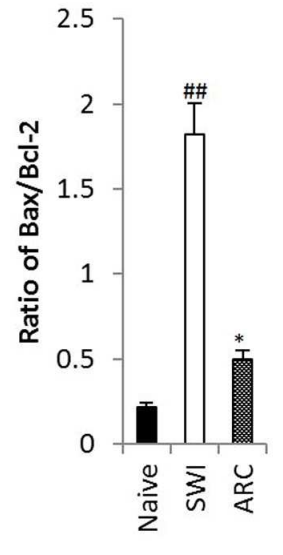

FIGURE 7 | Changes of gene expression in injured brain after ARC administration. Total RNA was extracted from injured brain tissue at 3 and 7 dpi. mRNA expression of IL-6, IL-10 and TNF- $\alpha$ was examined at 3 dpi, and Bax, Bcl-2, and Caspase-3 were examined at 7 dpi. (A) mRNA expression revealed by RT-PCR. (F) Quantitative analysis of the ratio of Bax/Bcl-2. (B-E) Quantitative analysis of mRNA Levels of TNF- $\alpha$, IL-6, IL-10, and Caspase-3. ARC administration up-regulated mRNA expression of IL-10, down-regulated mRNA expression of TNF- $\alpha$, IL-6, and Caspase-3, and reduced the ratio of Bax to Bcl-2 significantly compared to the untreated control. The data are presented as the mean $\pm \mathrm{SD}, n=6$ per group. ${ }^{\# \#} P<0.01$ vs. naive control; ${ }^{*} P<0.05,{ }^{* *} P<0.01$, vs. SWI control.

neutrophil infiltration and microglia activation after brain injury (Wang et al., 2007; Clausen et al., 2009). The number of neuroinflammatory cells can predict the extent of brain recovery. However, the term neuroinflammation generally refers to more chronic, sustained injury while the responses of microglial cells contribute to and expand the neurodestructive effects, worsening the disease process (Streit, 2006). Microglia can activate the proinflammatory cytokines IL- $1 \alpha$, IL- $1 \beta$, and TNF- $\alpha$ in the CNS (Wood, 2003). Proinflammatory cytokines such as TNF- $\alpha$ and IL- 6 are mainly produced by microglia, which in turn activate glia, further stimulating cytokine production and astrogliosis (Lau and Yu, 2001; Ziebell and MorgantiKossmann, 2010; Xia et al., 2012). In a previous report, ARC had significantly decreased MPO and EPO activities in injury tissues (Kang et al., 2008). Thus, in previous studies and in this study, results suggest that ARC suppresses traumainduced inflammation by inhibiting microglia activation and neutrophil infiltration as well as the release of proinflammatory cytokines that can cause secondary damage to the brain after injury.
The expression of inflammatory cytokines TNF- $\alpha$, IL-6, and IL-10 was upregulated after injury. TNF- $\alpha$ and IL- 6 are proinflammatory cytokines (Wilson et al., 2005), and IL-10 is anti-inflammatory cytokine. Transgenic mice overexpressing IL-6 show enhanced neuroinflammation and brain damage (Campbell et al., 1993). TNF- $\alpha$ is a key cytokine in the inflammatory response caused by tissue destruction, bacterial infection and tumor cells (Aggarwal et al., 1985), and it can induce the occurrence of and worsen inflammation (Chen et al., 2006). The most important function of $\mathrm{IL}-10$ is to limit and eventually terminate the inflammatory response (Moore et al., 2001). In vitro, IL-10 can significantly decrease the secretion of proinflammatory cytokines, such as TNF$\alpha$ (Schmit et al., 2001). The data from Cuzzocrea et al. indicate that the reduction of TNF- $\alpha$ and IL-6 results in a decrease of secondary tissue injury (Genovese et al., 2008). In a previous study, ARC potently inhibited nitric oxide (NO), TNF- $\alpha$ and IL-6, but not cyclooxygenase (COX)2 expression and COX-2 activity, possibly constituting the anti-inflammatory mechanism of ARC (Zhao et al., 2009). 
The data from Kou et al. (2011) shows that ARC exerts its anti-inflammatory effect by inhibiting reactive oxygen species (ROS)-dependent signal transducer and activator of transcription (STAT) signaling through its antioxidant activity. ARC also significantly reduced the phosphorylation of STAT1, STAT3, and JAK2 in LPS-stimulated RAW264.7 cells (Kou et al., 2011). ARC not only inhibited LPS-increased IL-6 and TNF$\alpha$ expression in LPS-stimulated peritoneal macrophages but also increased LPS-reduced IL-10 and CD 204 expression (Hyam et al., 2013). Hence, excessive IL- 6 and TNF- $\alpha$-mediated inflammation is likely involved in the unfavorable outcomes associated with SWI. Based on the above data and these studies, ARC treatment partly blocks the increase in IL- 6 and TNF- $\alpha$ expression and promotes the increase in IL-10 expression at the molecular and gene level as a result of brain injury, providing additional evidence that ARC suppresses neuroinflammation via downregulation of IL- 6 and TNF- a and upregulation of IL-10.

The Nissl (Nissl, 1894) body is a type of alkaline substance that is widely distributed in various neurons, and it can be seen in the soma and dendrites of neurons though not in the axon or axon hillock (Thompson, 2000; Kühnel, 2003). Upon neuron damage, the number of Nissl bodies can be reduced or even disappear, thus the degree of damage of neurons can be observed by observation of the Nissl body (Zhao et al., 2014; Zhai et al., 2015). NFs are the most abundant cytoskeletal proteins in large myelinated axons (Hozumi et al., 1990; Perrot et al., 2008); specifically, NF-M is important for the stabilization of mature axons (Wood, 2003). NF-M expression is decreased in injured animals, indicating axonal loss. Neuron structure (perikaryon, axon, dendrite) will be destroyed after CED, leading to secondary injury. Secondary pathophysiological insults will cause delayed neuronal death in surrounding or distant regions (Stoica and Faden, 2010). We observed the number of Nissl staining neurons and NF$M$ expression around the cavity in injured animals, results show that ARC treatment increases the number of neurons and NF-M expression compared to untreated animals, providing structural evidence for the effects of ARC in promoting neuronal restoration and inhibiting apoptosis in the injured brain.

Caspase- 3 is a caspase protein that is encoded by the CASP3 gene. Caspase- 3 is activated in the apoptotic cell both by the extrinsic (death ligand) and the intrinsic (mitochondrial) pathways (Salvesen, 2002; Ghavami et al., 2009), and caspase3 activity induces apoptosis and will kill cells indiscriminately (Li et al., 1997; Boatright and Salvesen, 2003). The Bcl-2 family includes genes encoding the anti-apoptotic protein Bcl2 and the pro-apoptotic protein Bax (Youle and Strasser, 2008; Kotipatruni et al., 2011). Bax overexpression stimulates apoptosis and suppresses the recovery of injury (Gross et al., 1998), while the overexpression of $\mathrm{Bcl}-2$ inhibits neuronal apoptosis and promotes the recovery of neurological function (Allsopp et al., 1993; Fan et al., 2010). Bax upregulation and Bcl-2 downregulation increases the $\mathrm{Bax}$ to $\mathrm{Bcl}-2$ ratio; this may be directly associated with cytochrome $\mathrm{c}$ release (Adams and Cory, 1998). In this study, ARC treatment reduced the Bax to Bcl-2 ratio and caspase- 3 levels compared to untreated mice, providing insight into the mechanism underlying the anti-apoptotic effects of ARC.

Apoptosis is the process of programmed cell death (PCD) (Green, 2011). A form of traumatic cell death that results from acute cellular injury, apoptosis is a highly regulated and controlled process that confers advantages during an organism's lifecycle. However, excessive apoptosis causes atrophy. Among the induction of apoptosis, inflammation plays an important role (Saal, 1995; Lucas et al., 2006). TNF- $\alpha$ is a cytokine mainly produced by activated macrophages and is the major extrinsic mediator of apoptosis (Harper et al., 2003; Yan et al., 2013). IL-6 is a pro-inflammatory cytokine that can also induce cell death (Yao et al., 2015), While IL-10 is an antiinflammatory cytokine, it can also inhibit cellular apoptosis (Banz et al., 2002). In previous reports, ARC was shown to confer neuroprotective effects through anti-inflammatory and anti-apoptotic effects (Swarup et al., 2008). In the present study, we investigated the number of dead cells using a TUNEL assay and capsase- 3 expression around the cavity in injured animals. The results show that ARC treatment decreases the number of TUNEL + and caspase- $3+$ expressing cells compared to untreated animals, providing anti-inflammatory and antiapoptotic evidence for the effects of ARC in promoting neuronal protection in the injured brain. Thus, we conclude that the underling mechanism of apoptosis inhibition of ARC occurs through an anti-inflammatory process.

\section{CONCLUSION}

Arctigenin treatment protects against BBB damage and secondary brain injury via anti-inflammatory and anti-apoptotic mechanisms in an experimental cortical SWI model. This study demonstrates that ARC confers neuroprotection and improves long-term neurological outcomes after CED.

\section{AUTHOR CONTRIBUTIONS}

JY, TK, and JS designed and performed the experiments, drafted and revised the manuscript, and prepared the final version of the manuscript. NL, YX, YJ, JS, LK, YY, YJ, YY, SL, ZT, TK, and SZ performed the experiments and analyzed and interpreted the data. All authors read and approved the version submitted for publication.

\section{ACKNOWLEDGMENT}

This work was supported by the National Natural Science Foundation of China (grant No. 30572336 and 81173580). 


\section{REFERENCES}

Abbott, N. J., and Romero, I. A. (1996). Transporting therapeutics across the bloodbrain barrier. Mol. Med. Today 2, 106-113. doi: 10.1016/1357-4310(96)88720-X Adams, J. M., and Cory, S. (1998). The Bcl-2 protein family: arbiters of cell survival. Science 281, 1322-1326. doi: 10.1126/science.281.5381.1322

Aggarwal, B. B., Kohr, W. J., Hass, P. E., Moffat, B., Spencer, S. A., Henzel, W. J., et al. (1985). Human tumor necrosis factor. Production, purification, and characterization. J. Biol. Chem. 260, 2345-2354.

Allsopp, T. E., Wyatt, S., Paterson, H. F., and Davies, A. M. (1993). The protooncogene bcl-2 can selectively rescue neurotrophic factor-dependent neurons from apoptosis. Cell 73, 295-307. doi: 10.1016/0092-8674(93)90230-N

Banz, A., Pontoux, C., and Papiernik, M. (2002). Modulation of Fas-dependent apoptosis: a dynamic process controlling both the persistence and death of CD4 regulatory $\mathrm{T}$ cells and effector $\mathrm{T}$ cells. J. Immunol. 169, 750-757. doi: 10.4049/jimmunol.169.2.750

Başkaya, M. K., Rao, A. M., Doğan, A., Donaldson, D., and Dempsey, R. J. (1997). The biphasic opening of the blood-brain barrier in the cortex and hippocampus after traumatic brain injury in rats. Neurosci. Lett. 226, 33-36. doi: 10.1016/S0304-3940(97)00239-5

Bayir, H., Kochanek, P. M., and Clark, R. S. (2003). Traumatic brain injury in infants and children: mechanisms of secondary damage and treatment in the intensive care unit. Crit. Care Clin. 19, 529-549. doi: 10.1016/S07490704(03)00014-9

Bitto, A., Polito, F., Irrera, N., Calo, M., Spaccapelo, L., Marini, H. R., et al. (2012). Protective effects of melanocortins on short-term changes in a rat model of traumatic brain injury*. Crit. Care Med. 40, 945-951. doi: 10.1097/CCM.0b013e318236efde

Boatright, K. M., and Salvesen, G. S. (2003). Mechanisms of caspase activation. Curr. Opin. Cell Biol. 15, 725-731. doi: 10.1016/j.ceb.2003.10.009

Bobo, R. H., Laske, D. W., Akbasak, A., Morrison, P. F., Dedrick, R. L., and Oldfield, E. H. (1994). Convection-enhanced delivery of macromolecules in the brain. Proc. Natl. Acad. Sci. U.S.A. 91, 2076-2080. doi: 10.1073/pnas.91.6.2076

Campbell, I. L., Abraham, C. R., Masliah, E., Kemper, P., Inglis, J. D., Oldstone, M. B., et al. (1993). Neurologic disease induced in transgenic mice by cerebral overexpression of interleukin 6. Proc. Natl. Acad. Sci. U.S.A. 90, 10061-10065. doi: $10.1073 /$ pnas.90.21.10061

Casanova, F., Carney, P. R., and Sarntinoranont, M. (2014a). Effect of needle insertion speed on tissue injury, stress, and backflow distribution for convection-enhanced delivery in the rat brain. PLoS ONE 9:e94919. doi: 10.1371/journal.pone.0094919

Casanova, F., Carney, P. R., and Sarntinoranont, M. (2014b). In vivo evaluation of needle force and friction stress during insertion at varying insertion speed into the brain. J. Neurosci. Methods 37, 9-89. doi: 10.1016/j.jneumeth.2014.08.012

Chen, J. W., Chen, Y. H., and Lin, S. J. (2006). Long-term exposure to oxidized low-density lipoprotein enhances tumor necrosis factor- $\alpha$-stimulated endothelial adhesiveness of monocytes by activating superoxide generation and redox-sensitive pathways. Free Radic. Biol. Med. 40, 817-826. doi: 10.1016/j.freeradbiomed.2005.10.037

Clark, R. S., Chen, J., Watkins, S. C., Kochanek, P. M., Chen, M., Stetler, R. A., et al. (1997). Apoptosis-suppressor gene bcl-2 expression after traumatic brain injury in rats. J. Neurosci. 17, 9172-9182.

Clausen, F., Hånell, A., Björk, M., Hillered, L., Mir, A. K., Gram, H., et al. (2009). Neutralization of interleukin-1 $\beta$ modifies the inflammatory response and improves histological and cognitive outcome following traumatic brain injury in mice. Eur. J. Neurosci. 30, 385-396. doi: 10.1111/j.1460-9568.2009. 06820.x

Cole, J. T., Yarnell, A., Kean, W. S., Gold, E., Lewis, B., Ren, M., et al. (2011) Craniotomy: true sham for traumatic brain injury, or a sham of a sham? J. Neurotrauma 28, 359-369. doi: 10.1089/neu.2010.1427

d'Avila, J. C., Lam, T. I., Bingham, D., Shi, J., Won, S. J., Kauppinen, T. M., et al. (2012). Microglial activation induced by brain trauma is suppressed by post-injury treatment with a PARP inhibitor. J Neuroinflammation 9, 31. doi: 10.1186/1742-2094-9-31

Fan, J., Xu, G., Nagel, D. J., Hua, Z., Zhang, N., and Yin, G. (2010). A model of ischemia and reperfusion increases JNK activity, inhibits the association of BAD and 14-3-3, and induces apoptosis of rabbit spinal neurocytes. Neurosci. Lett. 473, 196-201. doi: 10.1016/j.neulet.2010.02.045
Fan, T., Jiang, W. L., Zhu, J., and Feng Zhang, Y. (2012). Arctigenin protects focal cerebral ischemia-reperfusion rats through inhibiting neuroinflammation. Biol. Pharm. Bull. 35, 2004-2009. doi: 10.1248/bpb.b12-00463

Farook, J. M., Shields, J., Tawfik, A., Markand, S., Sen, T., Smith, S. B., et al. (2013). GADD34 induces cell death through inactivation of Akt following traumatic brain injury. Cell Death Dis. 4:e754. doi: 10.1038/cddis.2013.280

Fernandes-Alnemri, T., Yu, J. W., Datta, P., Wu, J., and Alnemri, E. S. (2009). AIM2 activates the inflammasome and cell death in response to cytoplasmic DNA. Nature 458, 509-513. doi: 10.1038/nature07710

Gao, Z., Wen, Q., Xia, Y., Yang, J., Gao, P., Zhang, N., et al. (2014). Osthole augments therapeutic efficiency of neural stem cells-based therapy in experimental autoimmune encephalomyelitis. J. Pharmacol. Sci. 124, 54-65. doi: $10.1254 /$ jphs.13144FP

Genovese, T., Mazzon, E., Esposito, E., Di Paola, R., Caminiti, R., Meli, R., et al. (2008). Effect of thalidomide on signal transduction pathways and secondary damage in experimental spinal cord trauma. Shock 30, 231-240. doi: 10.1097/shk.0b013e318162d290

Ghavami, S., Hashemi, M., Ande, S. R., Yeganeh, B., Xiao, W., Eshraghi, M., et al. (2009). Apoptosis and cancer: mutations within caspase genes. J. Med. Genet. 46, 497-510. doi: 10.1136/jmg.2009.066944

Green, D. R. (2011). Means to an End: Apoptosis and Other Cell Death Mechanisms. Cold Spring Harbor, NY: Cold Spring Harbor Laboratory Press.

Gross, A., Jockel, J., Wei, M. C., and Korsmeyer, S. J. (1998). Enforced dimerization of BAX results in its translocation, mitochondrial dysfunction and apoptosis. EMBO J. 17, 3878-3885. doi: 10.1093/emboj/17.14.3878

Gu, Y., Qi, C., Sun, X., Ma, X., Zhang, H., Hu, L., et al. (2012). Arctigenin preferentially induces tumor cell death under glucose deprivation by inhibiting cellular energy metabolism. Biochem. Pharmacol. 84, 468-476. doi: 10.1016/j.bcp.2012.06.002

Harper, N., Hughes, M., MacFarlane, M., and Cohen, G. M. (2003). Fasassociated death domain protein and caspase- 8 are not recruited to the tumor necrosis factor receptor 1 signaling complex during tumor necrosis factorinduced apoptosis. J. Biol. Chem. 278, 25534-25541. doi: 10.1074/jbc.M3033 99200

Hirjak, D., Wolf, R. C., Stieltjes, B., Hauser, T., Seidl, U., Thiemann, U., et al. (2013). Neurological soft signs and brainstem morphology in first-episode schizophrenia. Neuropsychobiology 68, 91-99. doi: 10.1159/000350999

Hozumi, I., Chiu, F. C., and Norton, W. T. (1990). Biochemical and immunocytochemical changes in glial fibrillary acidic protein after sab wounds. Brain Res. 524, 64-71. doi: 10.1016/0006-8993(90)90492-T

Hu, Y., Wen, Q., Liang, W., Kang, T., Ren, L., Zhang, N., et al. (2013). Osthole reverses beta-amyloid peptide cytotoxicity on neural cells by enhancing cyclic AMP response element-binding protein phosphorylation. Biol. Pharm. Bull. 36, 1950-1958. doi: 10.1248/bpb.b13-00561

Hyam, S. R., Lee, I. A., Gu, W., Kim, K. A., Jeong, J. J., Jang, S. E., et al. (2013). Arctigenin ameliorates inflammation in vitro and in vivo by inhibiting the PI3K/AKT pathway and polarizing M1 macrophages to M2-like macrophages. Eur. J. Pharmacol. 708, 21-29. doi: 10.1016/j.ejphar.2013.01.014

Kang, H. S., Lee, J. Y., and Kim, C. J. (2008). Anti-inflammatory activity of arctigenin from Forsythiae Fructus. J. Ethnopharmacol. 116, 305-312. doi: 10.1016/j.jep.2007.11.030

Kastrup, A., Gröschel, K., Ringer, T. M., Redecker, C., Cordesmeyer, R., Witte, O. W., et al. (2008). Early disruption of the blood-brain barrier after thrombolytic therapy predicts hemorrhage in patients with acute stroke. Stroke 39, 2385-2387. doi: 10.1161/STROKEAHA.107.505420

Kong, L., Hu, Y., Yao, Y., Jiao, Y., Li, S., and Yang, J. (2015). The Coumarin Derivative osthole stimulates adult neural stem cells, promotes neurogenesis in the hippocampus, and ameliorates cognitive impairment in APP/PS1 transgenic mice. Biol. Pharm. Bull. 38, 1290-1301. doi: 10.1248/bpb.b15-00142

Kotipatruni, R. R., Dasari, V. R., Veeravalli, K. K., Dinh, D. H., Fassett, D., and Rao, J. S. (2011). p53-and Bax-mediated apoptosis in injured rat spinal cord. Neurochem. Res. 36, 2063-2074. doi: 10.1007/s11064-011-0530-2

Kou, X., Qi, S., Dai, W., Luo, L., and Yin, Z. (2011). Arctigenin inhibits lipopolysaccharide-induced iNOS expression in RAW264. 7 cells through suppressing JAK-STAT signal pathway. Int. Immunopharmacol. 11, 1095-1102. doi: 10.1016/j.intimp.2011.03.005

Kühnel, W. (2003). Color Atlas of Cytology, Histology, and Microscopic Anatomy. New York, NY: Thieme. 
Kurapati, K. R. V., Atluri, V. S. R., Samikkannu, T., and Nair, M. P. (2013). Ashwagandha (Withania somnifera) reverses $\beta$-amyloid 1-42 induced toxicity in human neuronal cells: implications in HIV-associated neurocognitive disorders (HAND). PLOS ONE 8:e77624. doi: 10.1371/journal.pone.007 7624

Kurapati, K. R. V., Samikkannu, T., Atluri, V. S. R., Kaftanovskaya, E., Yndart, A., and Nair, M. P. (2014). $\beta$-Amyloid 1-42, HIV-1 Ba-L (Clade B) infection and drugs of abuse induced degeneration in human neuronal cells and protective effects of ashwagandha (Withania somnifera) and its constituent Withanolide A. PLoS ONE 9:e112818. doi: 10.1371/journal.pone. 0112818

Lau, L. T., and Yu, A. C. H. (2001). Astrocytes produce and release interleukin-1, interleukin-6, tumor necrosis factor alpha and interferon-gamma following traumatic and metabolic injury. J. Neurotrauma 18, 351-359. doi: 10.1089/08977150151071035

Lee, J. Y., Cho, B. J., Park, T. W., Park, B. E., Kim, S. J., Sim, S. S., et al. (2010). Dibenzylbutyrolactone lignans from forsythia koreana fruits attenuate lipopolysaccharide-induced inducible nitric oxide synthetase and cyclooxygenase-2 expressions through activation of nuclear factor-KAPPA. B and mitogen-activated protein kinase in RAW264.7 cells. Biol. Pharm. Bull. 33, 1847-1853.

Lee, S. T., Chu, K., Jung, K. H., Kim, S. J., Kim, D. H., Kang, K. M., et al. (2008). Anti-inflammatory mechanism of intravascular neural stem cell transplantation in haemorrhagic stroke. Brain 131, 616-629. doi: 10.1093/brain/ awm306

Li, P., Nijhawan, D., Budihardjo, I., Srinivasula, S. M., Ahmad, M., Alnemri, E. S., et al. (1997). Cytochrome c and dATP-dependent formation of Apaf1/caspase-9 complex initiates an apoptotic protease cascade. Cell 91, 479-489. doi: 10.1016/S0092-8674(00)80434-1

Liu, S. J., Zou, Y., Belegu, V., Lv, L. Y., Lin, N., Wang, T. Y., et al. (2014). Cografting of neural stem cells with olfactory en sheathing cells promotes neuronal restoration in traumatic brain injury with an anti-inflammatory mechanism. J. Neuroinflamm. 11, 1-9. doi: 10.1186/1742-2094-11-66

Loftspring, M. C., Johnson, H. L., Feng, R., Johnson, A. J., and Clark, J. F. (2011). Unconjugated bilirubin contributes to early inflammation and edema after intracerebral hemorrhage. J. Cereb. Blood Flow Metab. 31, 1133-1142. doi: $10.1038 / \mathrm{jcbfm} .2010 .203$

Logsdon, A. F., Lucke-Wold, B. P., Turner, R. C., Huber, J. D., Rosen, C. L., and Simpkins, J. W. (2015). Role of microvascular disruption in brain damage from traumatic brain injury. Compr. Physiol. 5, 1147-1160. doi: 10.1002/cphy.c140057

Lu, M., Chen, J., Lu, D., Yi, L., Mahmood, A., and Chopp, M. (2003). Global test statistics for treatment effect of stroke and traumatic brain injury in rats with administration of bone marrow stromal cells. J. Neurosci. Methods 128, 183-190. doi: 10.1016/S0165-0270(03)00188-2

Lucas, S. M., Rothwell, N. J., and Gibson, R. M. (2006). The role of inflammation in CNS injury and disease. Br. J. Pharmacol. 147, S232-S240. doi: 10.1038/sj.bjp.0706400

Moore, K. W., de Waal Malefyt, R., Coffman, R. L., and O'Garra, A. (2001). Interleukin-10 and the interleukin-10 receptor. Annu. Rev. Immunol. 19, 683765. doi: 10.1146/annurev.immunol.19.1.683

Moxon-Emre, I., and Schlichter, L. C. (2011). Neutrophil depletion reduces blood-brain barrier breakdown, axon injury, and inflammation after intracerebral hemorrhage. J. Neuropathol. Exp. Neurol. 70, 218-235. doi: 10.1097/NEN.0b013e31820d94a5

Nicholson, C. (2001). Diffusion and related transport mechanisms in brain tissue. Rep. Prog. Phys. 64, 815. doi: 10.1088/0034-4885/64/7/202

Perrot, R., Berges, R., Bocquet, A., and Eyer, J. (2008). Review of the multiple aspects of neurofilament functions, and their possible contribution to neurodegeneration. Mol. Neurobiol. 38, 27-65. doi: 10.1007/s12035-0088033-0

Raghupathi, R., and Margulies, S. S. (2002). Traumatic axonal injury after closed head injury in the neonatal pig. J. Neurotrauma 19, 843-853. doi: $10.1089 / 08977150260190438$

Saal, J. S. (1995). The role of inflammation in lumbar pain. Spine 20, 1821-1827. doi: 10.1097/00007632-199508150-00013

Salvesen, G. S. (2002). Caspases: opening the boxes and interpreting the arrows. Cell Death Differ. 9, 3-5. doi: 10.1038/sj.cdd.4400963
Schmit, A., Carol, M., Robert, F., Bontems, P., Houben, J. J., Van Gossum, A., et al. (2001). Dose-effect of interleukin-10 and its immunoregulatory role in Crohn's disease. Eur. Cytokine Netw. 13, 298-305.

Shi, H., Wang, H. L., Pu, H. J., Shi, Y, J., Zhang, J., Zhang, W. T., and Gao, Y. Q. (2015). Ethyl pyruvate protects against blood-brain barrier damage and improves long-term neurological outcomes in a rat model of traumatic brain injury. CNS Neurosci. Ther. 21, 374-384. doi: 10.1111/cns.12366

Stoica, B. A., and Faden, A. I. (2010). Cell death mechanisms and modulation in traumatic brain injury. Neurotherapeutics 7, 3-12. doi: 10.1016/j.nurt.2009.10.023

Streit, W. J. (2006). Microglial senescence: does the brain's immune system have an expiration date? Trends Neurosci. 29, 506-510. doi: 10.1016/j.tins.2006.07.001

Susarla, B. T., Villapol, S., Yi, J. H., Geller, H. M., and Symes, A. J. (2014). Temporal patterns of cortical proliferation of glial cell populations after traumatic brain injury in mice. ASN Neuro 6:AN20130034. doi: 10.1042/AN20130034

Swarup, V., Ghosh, J., Mishra, M. K., and Basu, A. (2008). Novel strategy for treatment of Japanese encephalitis using arctigenin, a plant lignan. J. Antimicrob. Chemother. 61, 679-688. doi: 10.1093/jac/dkm503

Taya, K., Marmarou, C. R., Okuno, K., Prieto, R., and Marmarou, A. (2010). Effect of secondary insults upon aquaporin-4 water channels following experimental cortical contusion in rats. J. Neurotrauma 27, 229-239. doi: 10.1089/neu.2009.0933

Thompson, R. F. (2000). The Brain: A Neuroscience Primer. New York: Macmillan.

Tsai, W. J., Chang, C. T., Wang, G. J., Lee, T. H., Chang, S. F., Lu, S. C., et al. (2011). Arctigenin from Arctium lappa inhibits interleukin-2 and interferon gene expression in primary human T lymphocytes. Chin. Med. 6, 12. doi: 10.1186/1749-8546-6-12

Wang, J. (2010). Preclinical and clinical research on inflammation after intracerebral hemorrhage. Prog. Neurobiol. 92, 463-477. doi: 10.1016/ j.pneurobio.2010.08.001

Wang, Y., Moges, H., Bharucha, Y., and Symes, A. (2007). Smad3 null mice display more rapid wound closure and reduced scar formation after a stab wound to the cerebral cortex. Exp. Neurol. 203, 168-184. doi: 10.1016/j.expneurol. 2006.08.006

Wilson, M. R., Choudhury, S., and Takata, M. (2005). Pulmonary inflammation induced by high-stretch ventilation is mediated by tumor necrosis factor signaling in mice. Am. J. Physiol. Lung Cell. Mol. Physiol. 288, L599-L607. doi: 10.1152/ajplung.00304.2004

Wood, P. (ed.). (2003). Neuroinflammation: Mechanisms and Management. New York, NY: Springer Science \& Business Media.

Xia, L., Jiang, Z. L., Wang, G. H., Hu, B. Y., and Ke, K. F. (2012). Treatment with ginseng total saponins reduces the secondary brain injury in rat after cortical impact. J. Neurosci. Res. 90, 1424-1436. doi: 10.1002/jnr.22811

Xia, Y., Kong, L., Yao, Y., Jiao, Y., Song, J., Tao, Z., et al. (2015). Osthole confers neuroprotection against cortical stab wound injury and attenuates secondary brain injury. J. Neuroinflamm. 12, 155. doi: 10.1186/s12974-015-0373-x

Yan, J., Xiang, J., Lin, Y., Ma, J., Zhang, J., Zhang, H., et al. (2013). Inactivation of BAD by IKK inhibits TNF $\alpha$-induced apoptosis independently of NF-KB activation. Cell 152, 304-315. doi: 10.1016/j.cell.2012.12.021

Yang, J., Bridges, K., Chen, K. Y., and Liu, A. Y. C. (2008). Riluzole increases the amount of latent HSF1 for an amplified heat shock response and cytoprotection. PLoS ONE 3:e2864. doi: 10.1371/journal.pone.0002864

Yao, W., Gu, C., Shao, H., Meng, G., Wang, H., Jing, X., et al. (2015). Tetrahydroxystilbene glucoside improves TNF- $\alpha$-induced endothelial dysfunction: involvement of TGF $\beta /$ Smad pathway and inhibition of vimentin expression. Am. J. Chin. Med. 43, 183-198. doi: 10.1142/S0192415X15500123

Youle, R. J., and Strasser, A. (2008). The BCL-2 protein family: opposing activities that mediate cell death. Nat. Rev. Mol. Cell Biol. 9, 47-59. doi: 10.1038/nrm2308

Zhai, P. P., Xu, L. H., Yang, J. J., Jiang, Z. L., Zhao, G. W., Sun, L., et al. (2015). Reduction of inflammatory responses by l-serine treatment leads to neuroprotection in mice after traumatic brain injury. Neuropharmacology 95 , 1-11. doi: 10.1016/j.neuropharm.2015.02.026

Zhang, N., Kang, T., Xia, Y., Wen, Q., Zhang, X., Li, H., et al. (2012). Effects of salvianolic acid B on survival, self-renewal and neuronal differentiation of bone marrow derived neural stem cells. Eur. J. Pharmacol. 697, 32-39. doi: 10.1016/j.ejphar.2012.10.008

Zhang, N., Wen, Q., Ren, L., Liang, W., Xia, Y., Zhang, X., et al. (2013). Neuroprotective effect of arctigenin via upregulation of P-CREB in mouse 
primary neurons and human SH-SY5Y neuroblastoma cells. Int. J. Mol. Sci. 14, 18657-18669. doi: 10.3390/ijms140918657

Zhang, R., Liu, Y., Yan, K., Chen, L., Chen, X. R., Li, P., et al. (2013). Antiinflammatory and immunomodulatory mechanisms of mesenchymal stem cell transplantation in experimental traumatic brain injury. J. Neuroinflamm. 10, 106. doi: 10.1186/1742-2094-10-106

Zhang, W. Z., Jiang, Z. K., He, B. X., and Liu, X. B. (2015). Arctigenin protects against Lipopolysaccharide-induced pulmonary oxidative stress and inflammation in a mouse model via suppression of MAPK, HO-1, and iNOS signaling. Inflammation 38, 1406-1414. doi: 10.1007/s10753-0150115-3

Zhao, F., Wang, L., and Liu, K. (2009). In vitro anti-inflammatory effects of arctigenin, a lignan from Arctium lappa L., through inhibition on iNOS pathway. J. Ethnopharmacol. 122, 457-462. doi: 10.1016/j.jep.2009. 01.038

Zhao, G. W., Wang, Y., Li, Y. C., Jiang, Z. L., Sun, L., Xi, X., et al. (2014). The neuroprotective effect of modified "Shengyu" decoction is mediated through an anti-inflammatory mechanism in the rat after traumatic brain injury. J. Ethnopharmacol. 151, 694-703. doi: 10.1016/j.jep.2013.11.041
Zhao, Y., Luo, P., Guo, Q., Li, S., Zhang, L., Zhao, M., et al. (2012). Interactions between SIRT1 and MAPK/ERK regulate neuronal apoptosis induced by traumatic brain injury in vitro and in vivo. Exp. Neurol. 237, 489-498. doi: 10.1016/j.expneurol.2012.07.004

Ziebell, J. M., and Morganti-Kossmann, M. C. (2010). Involvement of pro-and antiinflammatory cytokines and chemokines in the pathophysiology of traumatic brain injury. Neurotherapeutics 7, 22-30. doi: 10.1016/j.nurt.2009.10.016

Conflict of Interest Statement: The authors declare that the research was conducted in the absence of any commercial or financial relationships that could be construed as a potential conflict of interest.

Copyright ( 2016 Song, Li, Xia, Gao, Zou, Kong, Yao, Jiao, Yan, Li, Tao, Lian, Yang and Kang. This is an open-access article distributed under the terms of the Creative Commons Attribution License (CC BY). The use, distribution or reproduction in other forums is permitted, provided the original author(s) or licensor are credited and that the original publication in this journal is cited, in accordance with accepted academic practice. No use, distribution or reproduction is permitted which does not comply with these terms. 